\title{
Genome-wide transcriptional profiling of Botrytis cinerea genes targeting plant cell walls during infections of different hosts
}

\section{Barbara Blanco-Ulate 1,2 , Abraham Morales-Cruz' ${ }^{1}$, Katherine C. H. Amrine ${ }^{1}$, John M. Labavitch ${ }^{2}$, Ann L. T. Powell ${ }^{2}$ and Dario Cantu ${ }^{1 *}$}

' Department of Viticulture and Enology, University of California, Davis, Davis, CA, USA

2 Department of Plant Sciences, University of California, Davis, Davis, CA, USA

\section{Edited by:}

Vincenzo Lionetti, Sapienza

Università di Roma, Italy

Reviewed by:

Barbara De Coninck, University of

Leuven (KU Leuven), Belgium

Carmen González Bosch,

Universidad de Valencia, Spain

*Correspondence:

Dario Cantu, Department of

Viticulture and Enology, University of California, Davis, One Shields Ave.,

Davis, CA 95616, USA

e-mail:dacantu@ucdavis.edu
Cell walls are barriers that impair colonization of host tissues, but also are important reservoirs of energy-rich sugars. Growing hyphae of necrotrophic fungal pathogens, such as Botrytis cinerea (Botrytis, henceforth), secrete enzymes that disassemble cell wall polysaccharides. In this work we describe the annotation of 275 putative secreted Carbohydrate-Active enZymes (CAZymes) identified in the Botrytis B05.10 genome. Using RNAseq we determined which Botrytis CAZymes were expressed during infections of lettuce leaves, ripe tomato fruit, and grape berries. On the three hosts, Botrytis expressed a common group of 229 potentially secreted CAZymes, including 28 pectin backbone-modifying enzymes, 21 hemicellulose-modifying proteins, 18 enzymes that might target pectin and hemicellulose side-branches, and 16 enzymes predicted to degrade cellulose. The diversity of the Botrytis CAZymes may be partly responsible for its wide host range. Thirty-six candidate CAZymes with secretion signals were found exclusively when Botrytis interacted with ripe tomato fruit and grape berries. Pectin polysaccharides are notably abundant in grape and tomato cell walls, but lettuce leaf walls have less pectin and are richer in hemicelluloses and cellulose. The results of this study not only suggest that Botrytis targets similar wall polysaccharide networks on fruit and leaves, but also that it may selectively attack host wall polysaccharide substrates depending on the host tissue.

Keywords: Botrytis, noble rot, plant pathogenic fungi, CAZymes, RNAseq, tomato, grape, lettuce

\section{INTRODUCTION}

The cell wall matrix is one of the first and largest plant structures that pathogens encounter when interacting with potential hosts. The composition and architecture of cell walls vary between plant species, organs and developmental stages. Two co-extensive networks of polysaccharides comprise up to $80 \%$ of the mass of most plant cell walls. A network of cellulose microfibrils is cross-linked via hydrogen-bonded hemicelluloses and is embedded within a second network, a matrix of simple and branched pectin polysaccharides (Carpita and Gibeaut, 1993). The integrity of the hemicellulose-cellulose microfibril network provides much of the strength and rigidity of the cell wall (Harris and Stone, 2008; Scheller and Ulvskov, 2010). The pectin network influences the wall's porosity and provides structural coherence (Ishii et al., 2001; Vincken et al., 2003). Homogalacturonan (HG) and rhamnogalacturonans (RGI and RG-II) are the major pectins of the primary walls of dicots and non-graminaceous monocots (Voragen et al., 2009). Pectins are important for cell-to-cell adhesion and they are particularly abundant in the middle lamella and corners between adjacent cells (Mohnen, 2008). Structural glycoproteins, soluble proteins, ions and metabolites are also located within the polysaccharide networks of most cell walls (Cassab, 1998; Keegstra, 2010).

Plant cell walls that are recalcitrant to decomposition by microorganisms and walls that favor the timely activation and correct allocation of host defenses are more likely to resist pathogen infections (Cantu et al., 2008a; Underwood, 2012). For example, plant cell wall-associated kinases and receptors are crucial to sense invading pathogens and to promptly induce immune responses, including structural reinforcements of the wall and production of anti-pathogen compounds (Cantu et al., 2008a; Hematy et al., 2009). Furthermore, pre-formed defense proteins (e.g., extracellular pathogenesis-related proteins) and their locations within the plant cell wall matrix contribute to processes that prime host tissues for resistance (Powell et al., 2000; Cantu et al., 2008b).

Necrotrophic pathogens, such as Botrytis, have evolved complex strategies to overcome the plant immune system (Weiberg et al., 2013) and to destroy the pectin-rich middle lamellae and primary cell walls of the host, inducing cell death and compromising the integrity of host tissues (Tiedemann, 1997; Van Baarlen et al., 2004; Cantu et al., 2008a; Curvers et al., 2010). Botrytis is considered a generalist pathogen because it is capable of 
infecting a wide variety of plant hosts and organs. During infections, Botrytis secretes diverse proteins and enzymes that modify the host cell walls (Van Kan, 2006; Zhang and van Kan, 2013a). Some of these proteins, such as the polygalacturonase BcPG1, have been demonstrated to be important virulence factors in multiple host tissues (Ten Have et al., 1998; Valette-Collet et al., 2003; Espino et al., 2005; Kars et al., 2005a; Brito et al., 2006; Nafisi et al., 2014). Characterizing the cell wall-degrading enzymes deployed by Botrytis on different hosts and tissues may help identify virulence functions that Botrytis uses on all hosts and those that are important on specific hosts, organs, or developmental stages.

The Carbohydrate-Active enZymes (CAZymes) are proteins with predicted catalytic and carbohydrate-binding modules that degrade, modify, or create glycosidic bonds. Therefore, some CAZymes are candidates for proteins that participate in the modification and breakdown of cell wall polysaccharides (Cantarel et al., 2009). The assignment of a gene to a particular CAZyme family can predict the catalytic properties of the protein it encodes and its possible substrates (Cantarel et al., 2009; Park et al., 2010). Sequence homology to known CAZyme genes in combination with computational prediction of protein secretion (SignalP; Petersen et al., 2011) has been used extensively for in silico identification and classification of the repertoire of cell wall degrading enzymes of pathogenic fungi with sequenced genomes (Floudas et al., 2012; Suzuki et al., 2012; Blanco-Ulate et al., 2013a,b,c,d).

Genome-wide transcriptional profiling approaches have been applied successfully to study the regulation of pathogen virulence factors in plant hosts (Noël et al., 2001; Ithal et al., 2007; Jeon et al., 2007; O'Connell et al., 2012; Schmidtke et al., 2012; Cantu et al., 2013; Wiemann et al., 2013; Zhang et al., 2013). In this study we (i) identified in the current release of the publically available Botrytis genome (strain B05.10 v.1; Amselem et al., 2011) genes encoding putatively secreted CAZymes, (ii) analyzed the phylogenetic relationships of these genes, and (iii) profiled their expression when Botrytis interacts with three plant hosts. The plant hosts chosen for this study, ripe tomato fruit, ripe grape berries and lettuce leaves, represent to important postharvest commodities, which are highly susceptible to infections by Botrytis. Our results suggest that Botrytis not only expresses a rich repertoire of activities that target the many diverse structures of the plant cell walls, but also that some of these functions are differentially regulated depending on the host.

\section{MATERIALS AND METHODS ANNOTATION OF BOTRYTIS CAZymes}

Transcriptome sequences of Botrytis cinerea (strain B05.10 v.1; Amselem et al., 2011) were obtained from http://www.broadin stitute.org/annotation/genome/botrytis_cinerea. The transcriptome was annotated for sequences encoding Carbohydrate-Active enZymes (CAZymes; http://www.cazy.org) with the CAZymes Analysis Toolkit (http://mothra.ornl.gov/cgi-bin/cat/cat.cgi; Park et al., 2010) with an e value $<1 \mathrm{e}-2$, a bit score threshold of 55 and a rule level of support of 40. Functional annotation of the CAZymes genes was carried out with Blast2GO v.2.7.1 (http:// www.blast2go.com/start-blast2go; Götz et al., 2008), which performed a BLASTx search against the non-redundant (nr) protein database of NCBI; default parameters were used. The predicted
CAZymes from Botrytis were then clustered in protein tribes based on sequence similarities using BLASTp alignments ( $e$-value $<1 \mathrm{e}-6)$ and Tribe-MCL (Enright et al., 2002) following methods described in Haas et al. (2009). The presence of secretion signal peptides was evaluated for all genes in the transcriptome using SignalP v.4.0 (http://www.cbs.dtu.dk/services/SignalP-4.0/; Petersen et al., 2011) with the following parameters: 0.50 D-cutoff values for SignalP-TM and 0.45 for SignalP-noTM.

One of the limitations of in silico analyses of secretion peptides is the occurrence of false positives and false negatives (Petersen et al., 2011; Melhem et al., 2013). SignalP v.4.0 was reported to have a higher false negative rate $(8.80 \%)$ than false positive rate $(3.30 \%)$ when predicting secretion signals in plant proteins (Melhem et al., 2013). A literature search of previously validated secreted Botrytis CAZymes was performed to identify possible false negatives resulting from the SignalP prediction. Two CAZyme-encoding genes, BcPME1 (BC1G_06840) and BcXyn11A (BC1G_02167), had SignalP prediction scores below the $0.50 / 0.45$ $\mathrm{D}$-cutoff values, but both genes have been experimentally proven to encode secreted proteins (Valette-Collet et al., 2003; Kars et al., 2005b; Brito et al., 2006; Shah et al., 2009a,b; Fernández-Acero et al., 2010; Li et al., 2012); hence, they were included in the dataset of secreted Botrytis CAZymes. The existence of other false negatives still needs to be experimentally evaluated for each CAZyme that did not pass the SignalP thresholds.

\section{PHYLOGENETIC ANALYSES}

The protein sequences of 7 CAZyme subfamilies including genes with putative roles in degrading plant cell walls, based on manual curation of CAZymes and functional annotations, were analyzed. Multiple global sequence alignments were conducted with MUSCLE (Edgar, 2004) for all protein sequences in a particular tribe using default parameters. Phylogenetic analyses were conducted in MEGA v.5.2.2 (Tamura et al., 2011) using the NeighborJoining method with 1000 bootstrap replicates (Felsenstein, 1985; Saitou and Nei, 1987). All positions containing gaps and missing data were eliminated.

\section{BIOLOGICAL MATERIAL}

Tomato (Solanum lycopersicum) cv. Ailsa Craig was provided by the Tomato Genetics Research Center (UC Davis). Tomato plants were grown in the field in Davis, California. Fruit were tagged at 3 days post-anthesis (dpa) and harvested at the red ripe stage (42 dpa). The ripening stages of the fruit were confirmed by color, size and texture measurements.

The Botrytis strain B05.10 used to inoculate the tomato fruit was provided by Dr. J. A. L. van Kan (Department of Phytopathology, Wageningen University). Conidia were collected from sporulating cultures grown on $1 \%$ potato dextrose agar. Tomato fruit were disinfected and inoculated as in Cantu et al. (2008a). At the time of inoculation, fruit were wounded at seven sites to a depth of $2 \mathrm{~mm}$ and a diameter of $1 \mathrm{~mm}$. Wounded sites were inoculated with $10 \mu \mathrm{L}$ of a water suspension containing 5000 conidia. All fruit samples were incubated at $20^{\circ} \mathrm{C}$ in high humidity for 3 days. When material was collected for analysis, the tomato fruit were deseeded, frozen, and ground to fine powder in liquid nitrogen. Three biological replicates were produced; 
each replicate was an independent pool of 8-10 Botrytis-infected tomato fruit.

Ripe (23 brix) grape berries (Vitis vinifera cv. Sémillon) showing the initial symptoms of Botrytis infections were collected from the Dolce Winery Vineyards (Napa Valley, California). Fruit were field inoculated by spraying conidia of the Botrytis strain $\mathrm{BcDW} 1$ (Blanco-Ulate et al., 2013a). Transcript polymorphisms detected in the RNAseq data suggest that other strains also infected the berries in the vineyard (results not shown). Determination of the initial stage of Botrytis infection (S1) was based on the time at which individual berries showed a partial color change from green to pink, but the berries still maintained their turgor and tissue integrity. The $\mathrm{S} 1$ stage of botrytized-grape berries was confirmed by the amount of fungal biomass present in the berries (described below). On the same day of harvest, individual infected grape berries were deseeded, frozen, and ground to fine powder in liquid nitrogen. Four biological replicates were generated from independent pools of 10-15 Botrytis-infected grape berries.

\section{BOTRYTIS BIOMASS DETERMINATION}

Fungal biomass was quantified using the QuickStix Kit for Botrytis (EnviroLogix), which utilizes the monoclonal antibody BC12.CA4 (Meyer and Dewey, 2000) as described by Cantu et al. (2008b). One gram of ground tissue (pericarp and epidermis) from each biological replication was suspended in the kit buffer, $1: 40 \mathrm{~m} / \mathrm{v}$ for tomato fruit and $1: 20 \mathrm{~m} / \mathrm{v}$ for grape berries. The amount of material that cross-reacted with the antibody was measured in $500 \mu \mathrm{l}$ of the tissue suspension. The intensity of the test line was determined with the QuickStix reader (Envirologix) and converted into fungal biomass $(\mu \mathrm{g} / \mathrm{gFW}$ of fruit) based on standard curves using known amounts of dry mycelium diluted into extracts of healthy tomato fruit tissue (Cantu et al., 2009a).

\section{RNA SEQUENCING AND DATA PROCESSING}

Total RNA was extracted from two grams of infected tissues (pericarp and epidermis) from each biological replicate as described in Blanco-Ulate et al. (2013e). RNA concentration and purity were measured using the NanoDrop 2000c Spectrophotometer (Thermo Scientific). RNA integrity was checked by agarose gel electrophoresis. The Illumina TruSeq RNA Sample preparation Kit v.2 was used to prepare cDNA libraries from $4 \mu \mathrm{g}$ of total RNA. Libraries were barcoded individually and analyzed with the High Sensitivity DNA Analysis Kit using an Agilent 2100 Bioanalyzer (Agilent Technologies). Sequencing was carried out on an Illumina HiSeq machine at the DNA Technologies Service Core at UC Davis. The Illumina raw reads were deposited in the National Center for Biotechnology Information's Gene Expression Omnibus (GEO) and are accessible through GEO (GSE57588 accession; http://www.ncbi.nlm. nih.gov/geo/query/acc.cgi?acc=GSE57588). Quality trimming of raw reads was done with Sickle v.1.21 (https://github.com/ ucdavis-bioinformatics/sickle) with a threshold of $20(\mathrm{Q}>20)$ and adapter trimming was done with Scythe v.0.991 (https:// github.com/ucdavis-bioinformatics/scythe) with a prior of 0.4.

The sequences of the Botrytis (strain B05.10 v.1) and grape (v. 12X, http://www.genoscope.cns.fr/externe/Download/Projets/
Projet_ML/data/12X/annotation/) transcriptomes were combined and used as a reference for mapping Botrytis-infected grape reads. Likewise transcriptomes of Botrytis and tomato (ITAG2.3, $\mathrm{ftp}: / / \mathrm{ftp}$. solgenomics.net/tomato_genome/annotation/ITAG2.3_ release/) were merged and used as reference for Botrytis-infected tomato reads. Bowtie2 v.2.1.0 (Langmead and Salzberg, 2012) was used to align the processed reads to the combined references with the parameters-end-to-end-sensitive. Read counts were extracted from the bowtie 2 alignments using the script sam2counts.py v.0.91 (https://github.com/vsbuffalo/ sam2counts).

Raw counts of Botrytis genes expressed at 2 days post-infection of lettuce leaves were obtained from De Cremer et al. (2013). In this study, lettuce leaves (Lactuca sativa cv. Salinas) of 5 weekold plants were inoculated in the growth chamber with a spore suspension of Botrytis, strain B05.10 (De Cremer et al., 2013).

\section{DIFFERENTIAL EXPRESSION ANALYSES}

The Bioconductor package DESeq v. 1.14.0 (Anders and Huber, 2010) was used to normalize the raw transcript counts of Botrytis genes encoding potentially secreted CAZymes from infected lettuce leaves, ripe tomato fruit and grape berries. The DESeq pipeline was used to (i) compare the expression profiles of potentially secreted CAZymes during Botrytis infections of lettuce leaves, ripe tomato fruit and grape berries, and (ii) identify differentially expressed (DE) genes ( $P$-adjusted value $\leq 0.05)$.

\section{OUANTITATIVE REVERSE TRANSCRIPTION PCR (qRT-PCR)}

cDNA was prepared from the isolated RNA using the M-MLV Reverse Transcriptase (Promega). qRT-PCR was performed on a StepOnePlus PCR System using Fast SYBR Green Master Mix (Applied Biosystems). All qRT-PCR reactions were performed as follows: $95^{\circ} \mathrm{C}$ for $10 \mathrm{~min}$, followed by 40 cycles of $95^{\circ} \mathrm{C}$ for $3 \mathrm{~s}$ and $60^{\circ} \mathrm{C}$ for $30 \mathrm{~s}$. The BOTRYTIS RIBOSOMAL PROTEINLIKE5 (BCRPL5, BC1G_13576) was used as the reference gene and processed in parallel with the genes of interest. The primer sequences to amplify the $B c R P L 5, B c P G 1$, and $B c P G 2$ genes were obtained from Zhang and van Kan (2013b). Transcript levels for all genes in this study were linearized using the formula $2^{\text {(BCRPL5 CT-TARGET CT) }}$ as described in Chen and Dubcovsky (2012). Data presented are means of 3-4 biological replicates of infected tomato and grape berries.

\section{RESULTS}

\section{PREDICTED CAZYME BOTRYTIS GENES}

The genome of Botrytis cinerea (strain B05.10; Amselem et al., 2011) is predicted to encode 1155 CAZymes based on a similarity search against the entire non-redundant sequences of the CAZy database using the CAZYmes Analysis Toolkit (Park et al., 2010; Supplemental Table S1). Putative secretion signals were found in 275 CAZyme Botrytis genes (SignalP v4.0; Petersen et al., 2011). Glycoside hydrolases (GHs) were the most abundant class of putative secreted CAZymes (48.72\%); among the GHs, the GH28 subfamily was the largest group ( $14.18 \%$ of all GHs). Twenty-three percent of the CAZyme genes encoded carbohydrate-binding proteins (CBMs), $16.48 \%$ coded for carbohydrate esterases (CEs) and 8.06 and $3.30 \%$ encoded glycosyltransferases (GTs) and 
polysaccharide lyases (PLs), respectively. Eighty-eight of these CAZy proteins were previously detected in the secretomes of Botrytis-infected tomato fruit and Botrytis grown in host-free culture systems (Supplemental Table S2; Shah et al., 2009a,b; Espino et al., 2010; Fernández-Acero et al., 2010; Li et al., 2012; Shah et al., 2012.)

Of the 275 potentially secreted CAZymes, 121 were grouped into 39 protein tribes (containing at least two proteins; Supplemental Table S2). Protein tribes are protein families defined by their sequence similarity using the Tribe-MCL algorithm (Enright et al., 2002). Members within a protein tribe are predicted to have similar molecular structures and, thus, may perform similar biochemical functions. In most cases, proteins of the same tribe share a common evolutionary history (Enright et al., 2003). The largest tribes had 6-7 proteins and belonged to the CAZyme subfamilies CE10 (tribes 0 and 2), GH28 (tribe 1), CBM1 (tribe 3), GH3 (tribe 4), and GH16 (tribe 5). Tribe 1 contained the well-characterized endo-polygalacturonases (endoPGs, BcPG1-6), which cleave the homogalacturonan (HG pectin backbones; Jayani et al., 2005). Tribes 4 and 6 included, respectively, all putative $\beta$-glucosidases and xyloglucan (XyG) transglucosylase/hydrolases (XTHs) present in the Botrytis genome. Both the $\beta$-glucosidases and XTHs classes target the backbones of XyGs; $\beta$-glucosidases may be also involved in cellulose degradation (Eklöf and Brumer, 2010).

\section{RNA SEQUENCING (RNAseq) OF BOTRYTIS-INFECTED PLANT TISSUES}

RNAseq was performed to characterize the expression profiles of Botrytis genes encoding CAZymes during infections of ripe tomato fruit and grape berries. mRNA was isolated from Botrytisinfected tomato fruit (at 3 days post-inoculation, dpi) and grape berries (stage S1; see Methods) and analyzed by high-throughput sequencing. RNAseq data from lettuce leaves 2 days after Botrytis infection (De Cremer et al., 2013) were analyzed in parallel to the fruit data, in order to detect commonalities and differences of CAZyme expression between fungal infections of different host organs and species. A summary of parsed reads from each biological replication of the three Botrytis-infected plant hosts and the number of reads mapped to the Botrytis (strain B05.10) and plant transcriptomes is provided in Table 1.

The reads that uniquely mapped to the Botrytis transcriptome corresponded to more than $75 \%$ of the total predicted genes in the Botrytis genome. 12,766 (77.79\%), 12,998 (79.21\%) and 13,898 $(84.69 \%)$ Botrytis genes were detected in lettuce leaves, tomato fruit, and grape berries, respectively. In addition, the percentage of reads uniquely mapped to the Botrytis transcriptome relative to the total number of mapped reads suggested that the amounts of Botrytis were comparable between the infected hosts (Figure 1). Botrytis infections of ripe tomato fruit at $3 \mathrm{dpi}$, ripe grapes berries in stage 1 of the noble rot and lettuce leaves at 2 dpi showed similar disease symptoms, which include water-soaked lesions with no or limited fungal sporulation, and without extensive tissue maceration, suggesting that Botrytis was at similar stages in its life cycle on the three hosts.

The amounts of Botrytis biomass in the infected tomato and grape tissue samples were measured with a monoclonal antibodybased assay (Meyer and Dewey, 2000) and strongly correlated with the number of Botrytis transcript reads in the corresponding

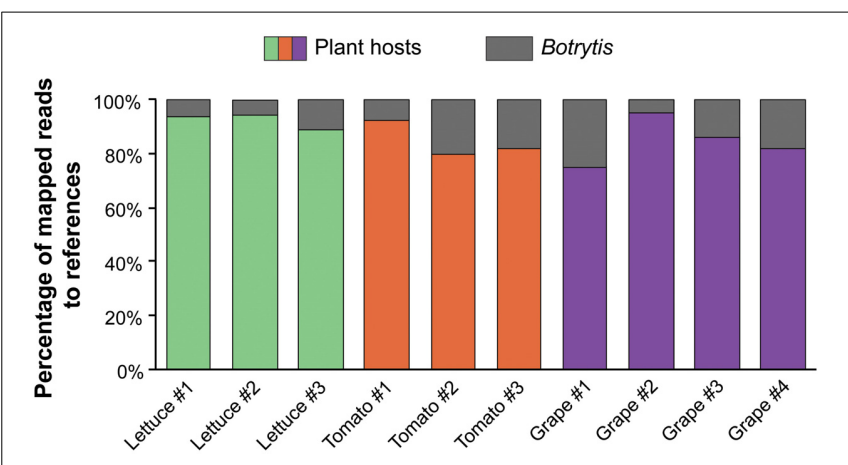

FIGURE 1 | Botrytis transcript abundance in infected plant tissues. Relative composition of RNAseq transcript reads between Botrytis and the three plant hosts (i.e., lettuce leaves, tomato fruit and grape berries).

Table 1 | Summary of trimmed and mapped reads of mRNA from Botrytis-infected tissues.

\begin{tabular}{|c|c|c|c|c|c|}
\hline Samples & Quality-trimmed reads $(0>20)$ & \multicolumn{2}{|c|}{ Total reads mapped } & \multicolumn{2}{|c|}{ Number of reads uniquely mapped } \\
\hline Lettuce \#1 & $20,726,205$ & $15,476,051$ & 74.67 & 981,495 & $14,494,556$ \\
\hline Lettuce \#2 & $8,742,262$ & $6,098,894$ & 69.76 & 324,147 & $5,774,747$ \\
\hline Lettuce \#3 & $7,024,911$ & $5,197,645$ & 73.99 & 566,381 & $4,631,264$ \\
\hline Tomato \#1 & $15,300,253$ & $12,693,894$ & 82.97 & 971,765 & $11,722,129$ \\
\hline Grape \#1 & $21,529,329$ & $16,579,455$ & 77.01 & $4,083,310$ & $12,496,145$ \\
\hline Grape \#2 & $25,706,831$ & $21,673,021$ & 84.31 & 983,846 & $20,689,175$ \\
\hline Grape \#3 & $22,110,864$ & $18,024,359$ & 81.52 & $2,490,373$ & $15,533,986$ \\
\hline Grape \#4 & $17,372,190$ & $13,796,319$ & 79.42 & $2,448,717$ & $11,347,602$ \\
\hline
\end{tabular}

Transcript reads from infected lettuce leaves were from De Cremer et al. (2013). 
samples (Supplemental Figure S1). This confirmed that the number of Botrytis transcripts from infected plant tissues determined by RNAseq can be used as an indicator of the amount of Botrytis biomass present in the infected tissues.

\section{CAZYme BOTRYTIS GENES EXPRESSED DURING HOST PLANT INFECTIONS}

Most $(88.40 \%)$ of the CAZyme genes predicted in the Botrytis genome were detected in the three infected hosts (Figure 2A; Supplemental Table S1). The genes commonly expressed in the three hosts include $83.23 \%$ of the CAZyme genes with predicted secretion signals (Figure 2A; Supplemental Table S2). The largest number of genes encoding putative secreted CAZymes belonged to the GH28 and CE10 subfamilies, each with 17 genes (Supplemental Table S2). Although CAZymes secreted by Botrytis are expected to target plant cell wall substrates, they could also be involved in remodeling the fungal cell wall as the pathogen grows and develops (Cantu et al., 2009b). Alternatively, they may degrade host cellular contents including starch and glycosylated proteins and secondary metabolites with sugar groups (Faure, 2002; Shah et al., 2009b; Klis et al., 2010). Some CAZymes can act on more than one polysaccharide substrate (Eklöf and Brumer, 2010). Table 2 provides an overview of Botrytis CAZymes that might be relevant for the degradation of plant cell walls, as determined by manual curation of their functional annotations.
Remarkably, 98.90\% of the CAZyme Botrytis genes with secretion signals were detected when the data of the transcriptomes from all the hosts were combined (Supplemental Table S2). Only three genes, BC1G_09963 (CBM50|CBM18|GH18 subfamily), $B C 1 G_{-} 13488$ (putative XTH, GH16 subfamily; tribe 5) and $B C 1 G \_13714$ (CE10 subfamily; tribe 0 ) were not found in any of the Botrytis-infected tissues.

CAZyme Botrytis genes that were detected on some but not all hosts (Supplemental Table S2) were identified. Thirteen percent of the genes encoding putative secreted CAZymes were expressed in infected ripe tomato fruit and grape berries but were not detected in infected lettuce leaves (Figure 2A; Supplemental Table S2). For example, three members of the GH16 subfamily (including two putative XTHs from tribe 5) were detected only on tomato fruit and grape berries. The well-described PG-coding gene BcPG2 (Kars et al., 2005a) was detected only in infected lettuce leaves and tomato fruit. Two genes (BC1G_05377 from the CBM18 subfamily and BC1G_15017 from the AA9 subfamily) were identified only in the transcriptomes of infected lettuce leaves and grape berries.

Besides the Botrytis genes that appeared to be preferentially expressed in infected fruit but not in infected lettuce leaves, a few other genes seemed to be specifically expressed in a particular plant species (Supplemental Table S2). Three genes were uniquely detected in infected ripe grape berries: a putative XTH (BC1G_09829, GH16 subfamily and tribe 5), a candidate

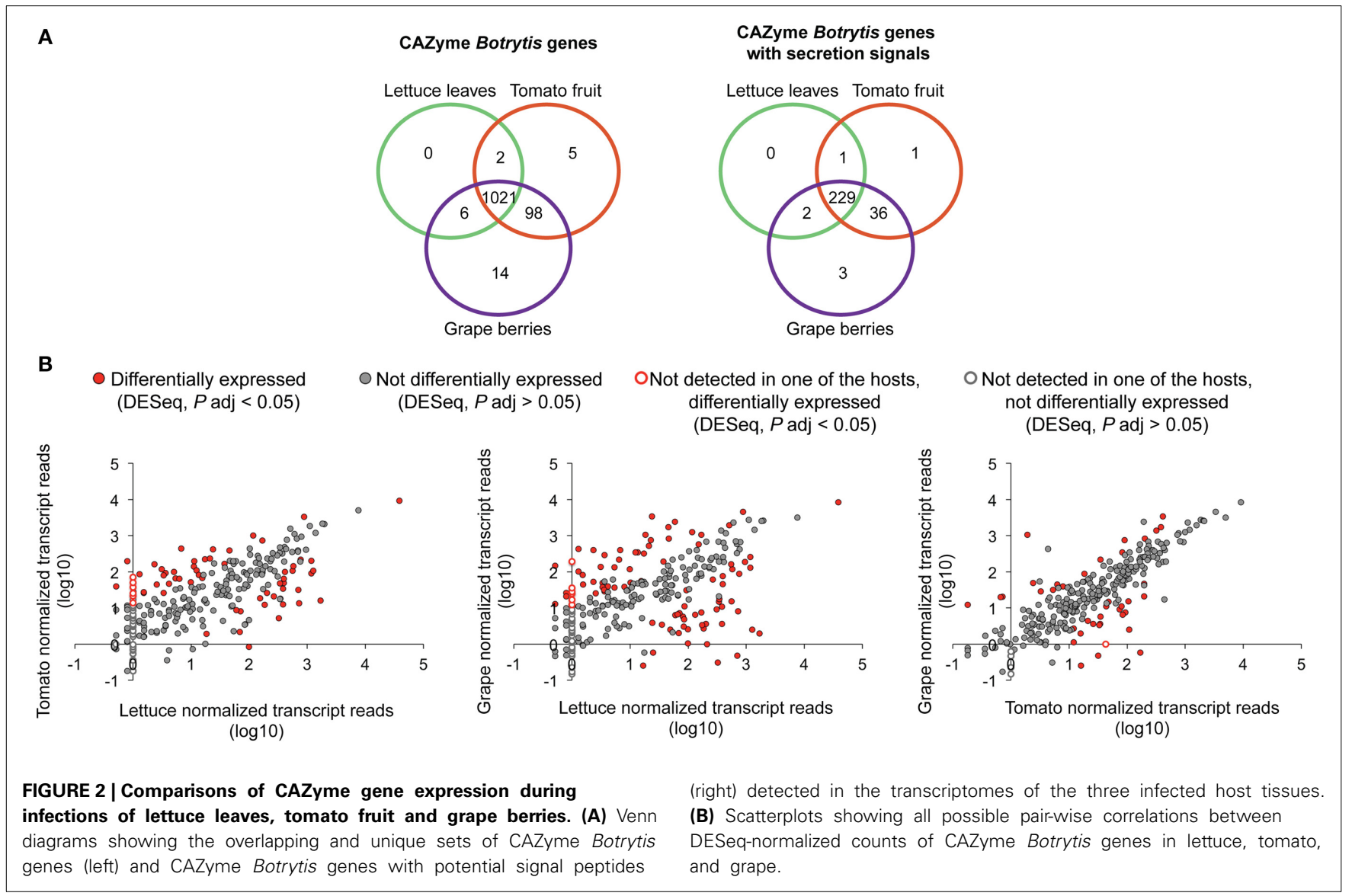


Table 2 | Annotated secreted Botrytis enzymes involved in plant cell wall disassembly.

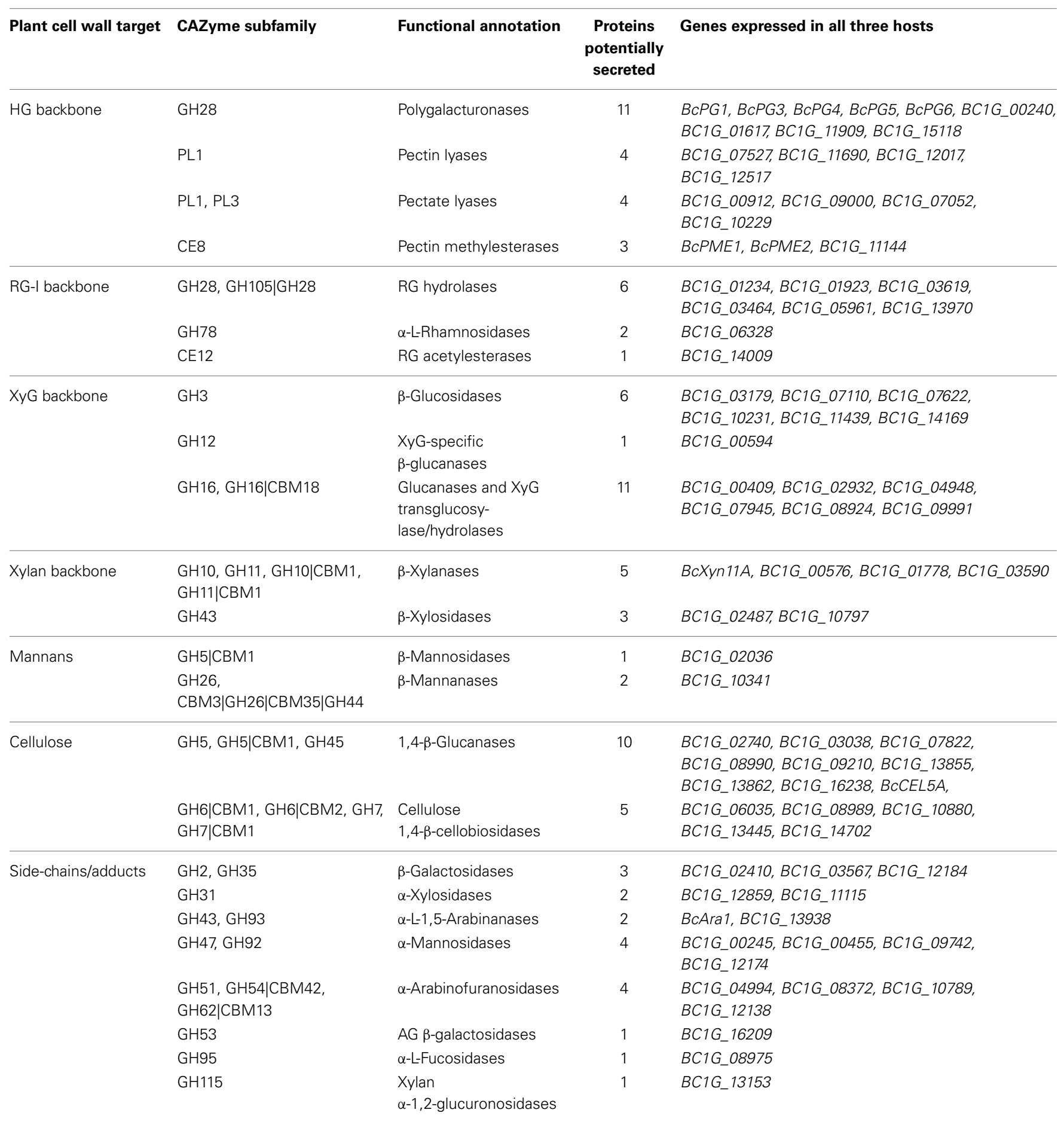

The secreted CAZyme-coding genes that were commonly expressed during Botrytis infections of lettuce leaves, tomato fruit and grape berries are presented.

copper-dependent lytic polysaccharide monooxygenase (LPMO, BC1G_00922, AA9 subfamily) and a predicted FAD-binding oxidoreductase (BC1G_06334, GT22 subfamily). One gene, a putative endo- $\beta$-1,4-xylanase (BC1G_13645, GH11 subfamily), was detected only in tomato fruit. No CAZyme Botrytis genes were detected exclusively in lettuce leaves.
The lowest number of CAZyme genes was detected in Botrytisinfected lettuce leaves (Figure 2A, Supplemental Tables S1 and S2). This observation could indicate that Botrytis expressed a smaller set of genes in lettuce leaves, or that differences in the experimental design (e.g., inoculations in laboratory conditions vs. field infections) or sequence coverage affected the detection 
levels. Some (23 genes) of the Botrytis genes that were not detected in infected lettuce leaves were genes with low levels $(<0.01 \%)$ of mapped reads in the other plant hosts, suggesting that these genes may not have been detected in lettuce leaves perhaps because of low coverage (Figure 2B). However, other Botrytis genes missing from the infected lettuce transcriptome (4 genes) had moderate to high levels of expression $(0.05-0.30 \%)$ in fruit tissues, indicating that they may not be relevant during lettuce infections (Figure 2B).

\section{RELATIVE GENE EXPRESSION OF BOTRYTIS CAZymes WITH SIGNAL PEPTIDES IN DIFFERENT HOST TISSUES}

Figure 3 describes the repertoire of potentially secreted CAZymes encoded in the Botrytis genome and their relative levels of expression (i.e., percentage of DESeq-normalized reads) when compared to the normalized expression of all CAZyme Botrytis genes with signal peptides in a given infected host tissue. Among the most highly expressed Botrytis genes coding for characterized or candidate plant cell wall modifying enzymes in each of the plant hosts, BcPG1 gene had the maximum level of expression during Botrytis infections on all hosts $(46 \%$ of reads in infected lettuce, $18.77 \%$ of reads in infected tomato fruit and $13.16 \%$ in botrytized-grape berries; Supplemental Table S2). Five other Botrytis genes also were highly expressed in the three hosts: a putative cellobiohydrolase gene (BC1G_14702, GH7|CBM1 subfamily), a candidate $\alpha$-xylosidase gene (BC1G_12859, GH31 subfamily), BcPME2 coding for a pectin methylesterase (PME, CE8 subfamily; Kars et al., 2005b), BcCel5A encoding an endo- $\beta$ glucanase (GH5 subfamily, Espino et al., 2005), and a putative endo-glucanase gene (BC1G_13862, GH45 subfamily).

Elevated expression ( $>0.50 \%$ of reads) of six genes encoding CAZymes with defined or putative roles in cell wall degradation was detected during infections of ripe fruit (tomato and grape), but not during infections of lettuce leaves (Supplemental Table S2). These putative fruit-specific genes include two genes encoding putative copper-dependent LPMOs (BC1G_07653 and $B C 1 G \_07658$, AA9 subfamily, $P$-adjusted value $\left.<0.005\right)$.

Eight genes were highly expressed in lettuce leaves, but were expressed at lower levels in ripe fruit (Figure 3, Supplemental Table S2). These included a candidate $\alpha$-Larabinofuranosidase (BC1G_04994, GH54|CBM42 subfamily, $P$-adjusted value $<0.001)$, a predicted exo-PG (BC1G_01617, GH28 subfamily, $P$-adjusted value $<0.001$ ), and a possible $\beta$-glucosidase (BC1G_07110, GH3 subfamily, $P$-adjusted value $<0.001)$.

\section{ASSOCIATION BETWEEN EVOLUTIONARY HISTORY AND EXPRESSION LEVELS OF BOTRYTIS PROTEINS INVOLVED IN PLANT CELL DISASSEMBLY}

The evolutionary relationships among members of seven CAZyme subfamilies corresponding to characterized and putative cell wall modifying enzymes were inferred using the NeighborJoining method (Saitou and Nei, 1987; Figures 4, 6, 7; see Methods for details). The CAZyme subfamilies were chosen based on their functional annotations with the additional requirement of including protein tribes with more than three members.
The phylogenetic analyses of the GH28 subfamily, which included Botrytis proteins involved in the hydrolysis of pectins; i.e., HG and RG-I backbones, identified two main clades ( $86 \%$ bootstrap value; Figure 4A). The first clade included the endoPGs (tribe 1). The second clade was composed of two wellsupported groups (79\% bootstrap value); one group included the rhamnogalacturonan hydrolases (RGases) of the tribe 16, and the other group was comprised of exo-PGs and RGases from tribes 10 and 26, respectively. The consensus phylogenetic tree of the pectin lyases (PLs) and pectate lyases (PELs) from in the PL1 and PL3 subfamilies (Figure 4B) did not identify distinct clades, but confirmed the classification between protein tribes. For example, the PLs belonging to the tribe 8 group and the PELs, some of which corresponded to tribe 24, were separated in the tree. The PMEs from the CE8 subfamily (Figure 4C) showed a well-supported cluster (100\% bootstrap value) composed of the characterized BcPME1 and BcPME2 proteins; however, the tree also supported the grouping of the tribe 11, which also included BcPME3.

Botrytis endo-PG (tribe 1) and PME (tribe 11) genes had the highest levels of expression (Figures 4A,C, Supplemental Table S2). However, not all the members of these tribes were expressed equally on the three plant hosts. Among the members of tribe 1 , only the $B c P G 1$ gene was highly expressed in all hosts (Figure 4A). BcPG3 had elevated expression in botrytized grape berries (1.28\% of reads) but was expressed at lower levels in other infected host tissues ( $P$-adjusted value $<0.05$ ); whereas the BcPG6 gene was expressed more in infected lettuce leaves than on tomato fruit or grape berries ( $P$-adjusted value $<0.001$ ), and BcPG2 was not expressed during Botrytis infections of grape berries ( $P$-adjusted value $<0.001)$. The expression of the $B c P G 1$ and $B c P G 2$ genes were validated by quantitative reverse transcription PCR (qRT-PCR; Figure 5). A sequence alignment of the $B c P G 2$ gene of the B05.10 strain and the gene homolog of BcDW1 strain (primary inoculum used to induce noble rot in the grape berries; Blanco-Ulate et al., 2013a) indicated that they share $99.02 \%$ identity at the DNA level with no gaps. The mapping parameters used in this study were chosen to allow reads to map on a reference with a higher level of sequence diversity. To determine if sequence polymorphisms were responsible for the apparent lack of $B c P G 2$ expression, the RNAseq transcript reads from infected grapes were mapped to the predicted BcDW1 transcriptome and very similar mapping counts were obtained $(r>0.99 ; P$-value $=2.2 \mathrm{e}-16$; Supplemental Figure S2). The mapping coverage of BcPG2 using BcDW1 as transcriptomics reference confirmed the absence of expression of this gene during Botrytis infections of ripe grape berries.

Although transcripts of all BcPMEs were abundant in all plant tissues, Botrytis selectively expressed specific PME genes in each host: $B c P M E 2$ in lettuce leaves, BcPME1 in tomato fruit and $B c P M E 3$ in grape berries (Figure 4C, Supplemental Table S2). Hydrolases of the RG-I backbone (RGases; tribes 16 and 26) showed low levels of expression in all hosts, with the exception of BC1G_05961 that was expressed at higher level in ripe fruit when compared to lettuce leaves (Figure 4A, $P$-adjusted value $<0.001)$. On the other hand, BC1G_01617 was the only 


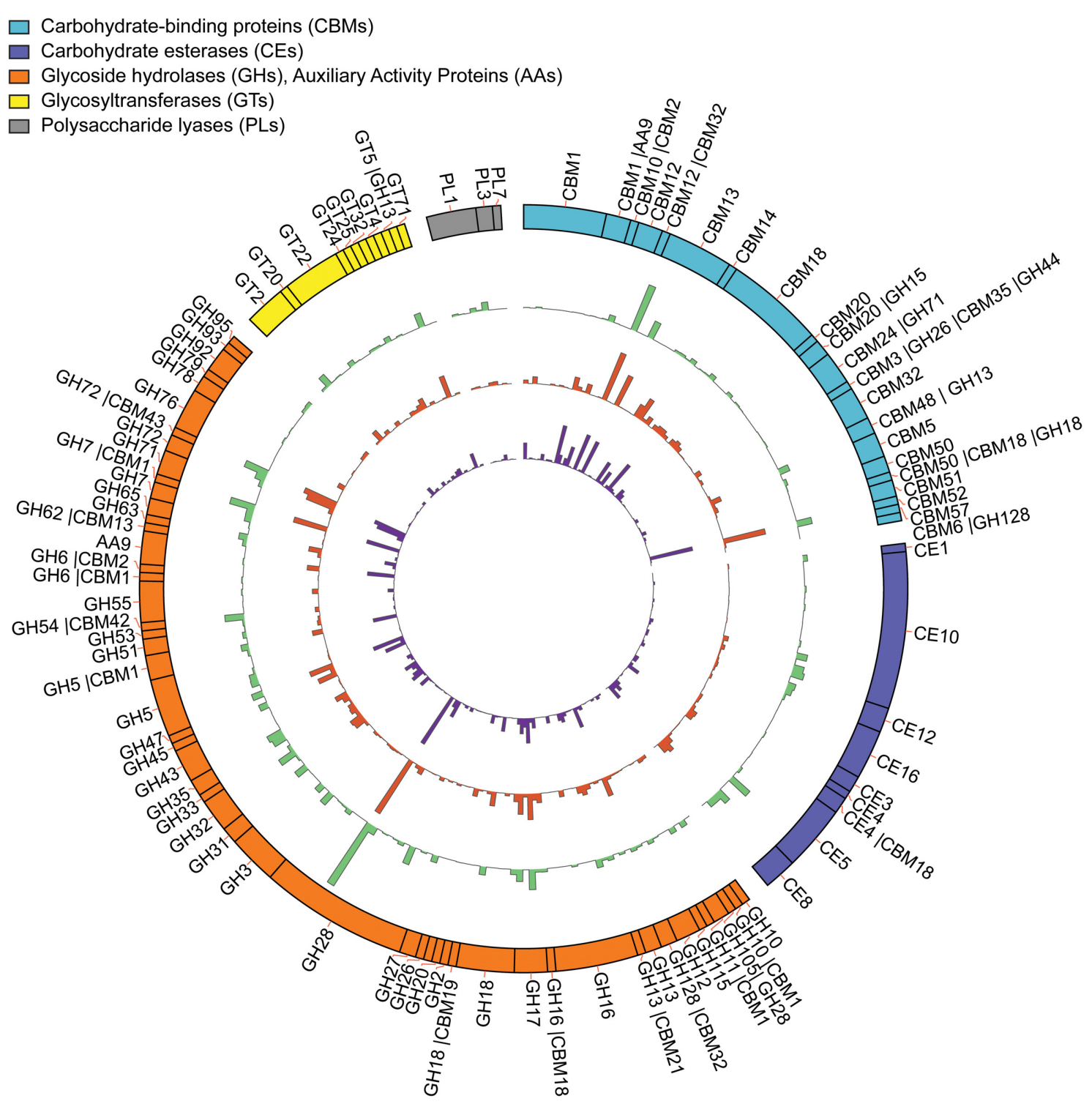

FIGURE 3 | Botrytis genes encoding predicted secreted CAZymes and their relative expression levels during infections of three plant hosts. The outermost ring represents all of the secreted CAZymes predicted in the Botrytis cinerea genome (strain B05.10). The inner four rings represent the relative expression of each CAZyme gene during Botrytis infections of lettuce leaves (green, second ring from outside), ripe tomato fruit (red, third ring from outside) and ripe grape berries (purple, the innermost ring). The relative expression of each gene is the log2-transformed percentage of normalized reads among the total normalized reads from all CAZyme Botrytis genes that possess a secretion signal peptide.
exo-PG (tribe 10) with considerable levels of expression in all hosts; the highest level of expression of this gene was in lettuce leaves ( $P$-adjusted value $<0.001$ ). Members of the PL1 and PL3 subfamilies, predicted to encode PLs and PELs, had low levels of expression $(<0.3 \%)$ in all plant hosts. The exception was the $B c P L$-like1 gene (tribe 8 ), which was more highly expressed in infected lettuce leaves than ripe tomato fruit (Figure 4B; $P$-adjusted value $<0.05)$.

Figure 6 depicts the phylogenetic relationships among the CAZymes that might have roles in the breakdown of XyGs and cellulose. These include putative XTHs and glucanases (GH16 subfamily), and $\beta$-glucosidases (GH3 subfamily). The consensus phylogenetic tree of the GH16 subfamily separated the putative XTHs (tribe 5) from glucanases. Most candidate XTHs (tribe 5) showed low levels of expression in the three host tissues; e.g., the BcXTH-like1 gene had an intermediate level of expression in ripe fruit tissues $(>0.35 \%$ reads in both tomato and grape hosts). Three possible glucanases (BC1G_00409, BC1G_04948, and BC1G_02932) from diverse tribes have high expression in the three host tissues (Supplemental Table S2).

The Botrytis proteins present in the AA9 subfamily include copper-dependent LPMOs proteins and other hypothetical proteins. Copper-dependent LPMOs are an auxiliary class of cell 


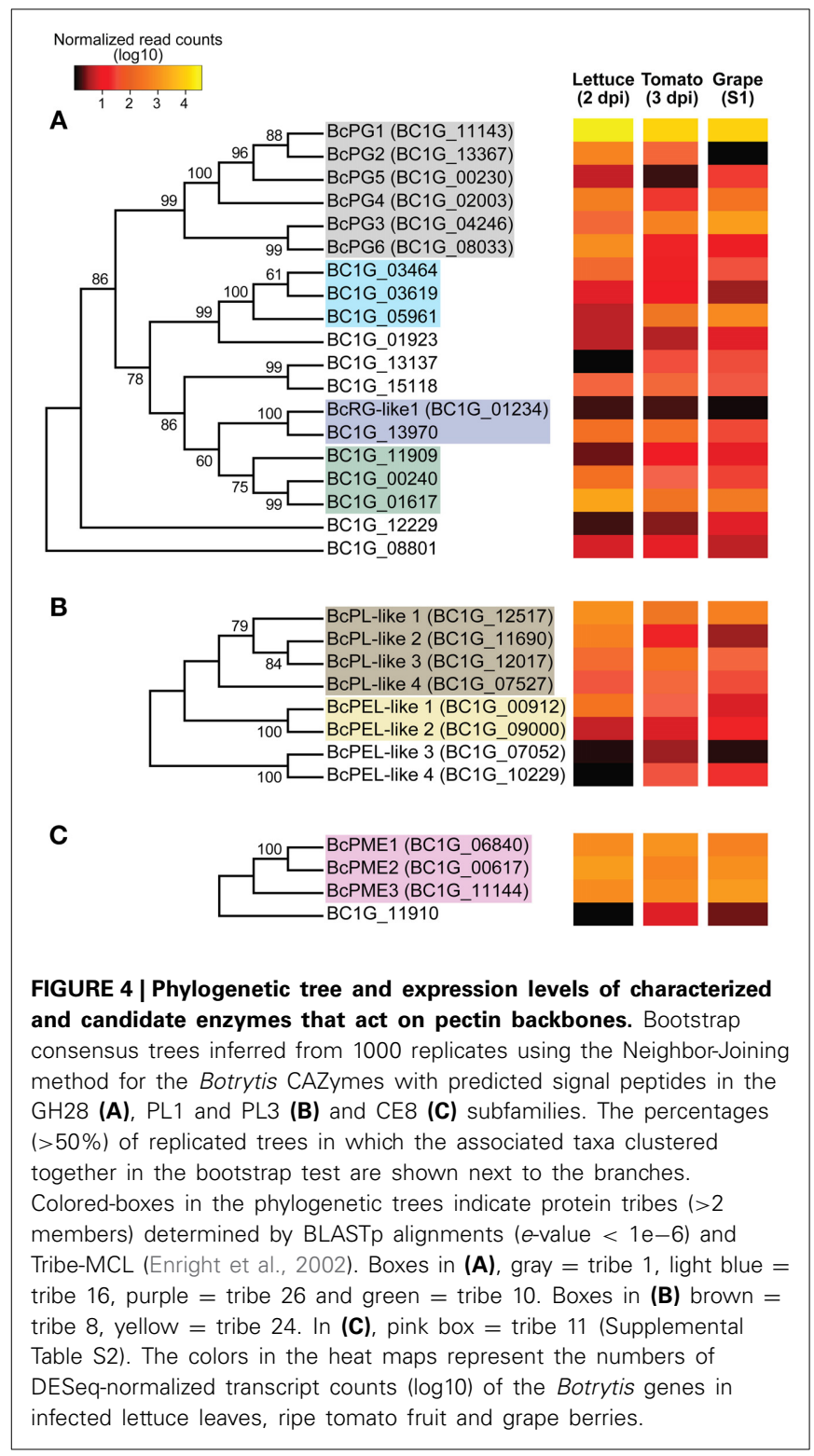

wall modifying proteins that may act on cellulose microfibrils. The phylogenetic analysis of the AA9 subfamily identified two potential clades, in one of which the LPMOs (tribe 13) grouped together. Two of these putative LPMOs (BC1G_07653 and BC1G_07658) showed elevated expression in Botrytisinfected fruit, particularly in grape berries (Figure 7A; mentioned before).

Phylogenetic and gene expression analyses were done with proteins from the CE5 subfamily, some of which are involved in plant cuticle degradation (Figure 7B). There were two monophyletic groups in the consensus phylogenetic tree of the CE5 subfamily. Tribe 15, which included the cutinases, BcCutA (Van Kan et al., 1997) and $B c C u t B$ (Leroch et al., 2013), formed a separate group from the proteins of tribe 31, which included CAZymes without clear functional annotations. On the other hand, proteins from tribe 31 clustered together with putative acetylxylan esterases, which catalyze the deacetylation of

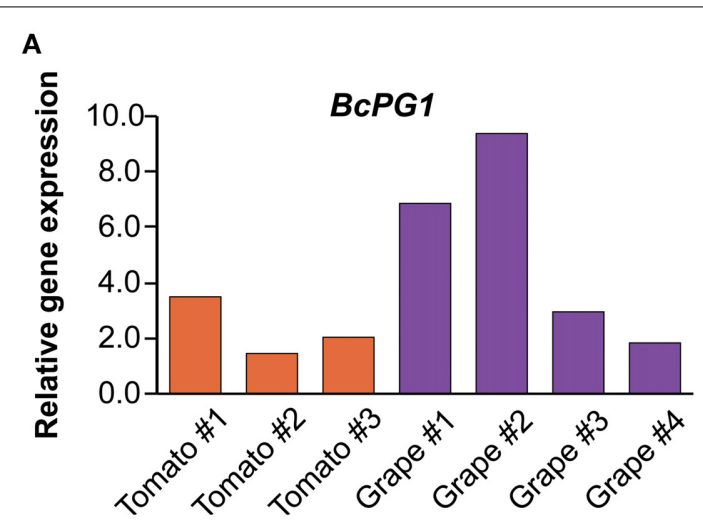

B

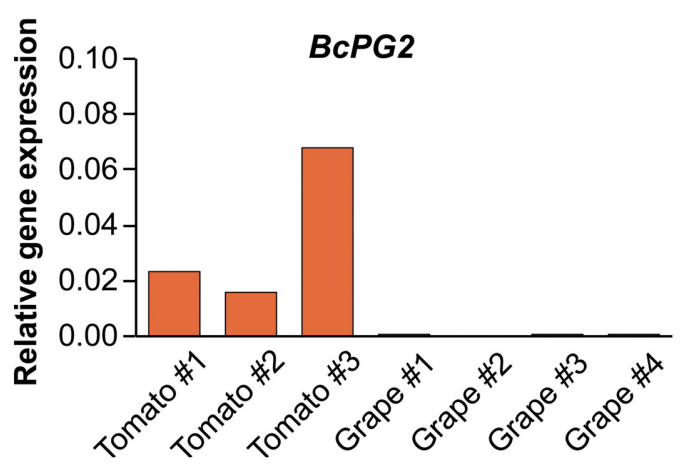

C

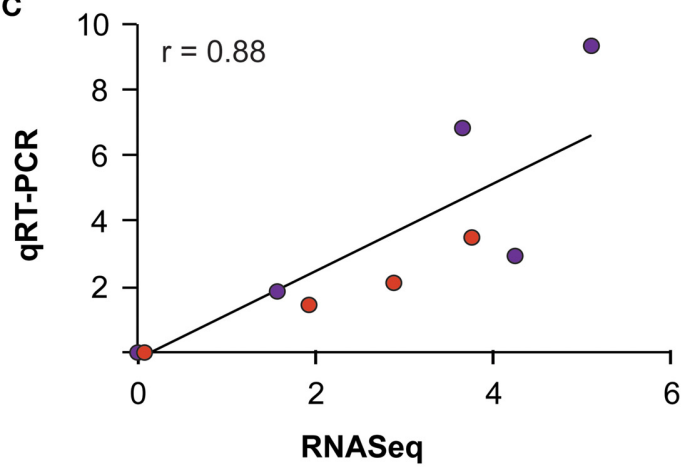

FIGURE 5 | qRT-PCR validation of the RNAseq expression results for $B c P G 1$ and $B c P G 2$ genes in ripe tomato fruit and grape berries. Relative expression levels of $B C P G 1$ (A) and $B C P G 2$ (B) measured in the biological replications of Botrytis-infected tomato fruit and botrytized-grape berries. (C) The scatterplot depicts the correlation between the qRT-PCR relative expression of $B C P G 1$ and $B C P G 2$ genes and their corresponding raw reads normalized against the same reference gene ( $B C R P L 5)$ used in the qRT-PCR analyses. The data points indicate that the $B C P G 2$ expression in grape berries were close to zero (average of $4.49 \mathrm{e}-5$ ) and in tomato fruit the expression was $3.57 \mathrm{e}-2$ on average; thus they overlapped in the graph. The Pearson correlation coefficient $(r)$ is presented $(P$-value $<0.001)$. A linear trend is shown.

xylan backbones, thus assisting, their subsequent degradation by hydrolytic enzymes. $B c C u t A$ gene was highly expressed $(>0.45 \%$ of reads) by Botrytis in fruit tissues ( $P$-adjusted value $<0.001)$, while a putative cutinase gene (BcCUT-like1) was more highly expressed (2.03\% of reads) during Botrytis infections of lettuce leaves (Figure 7B; $P$-adjusted value $<0.001$ ). 


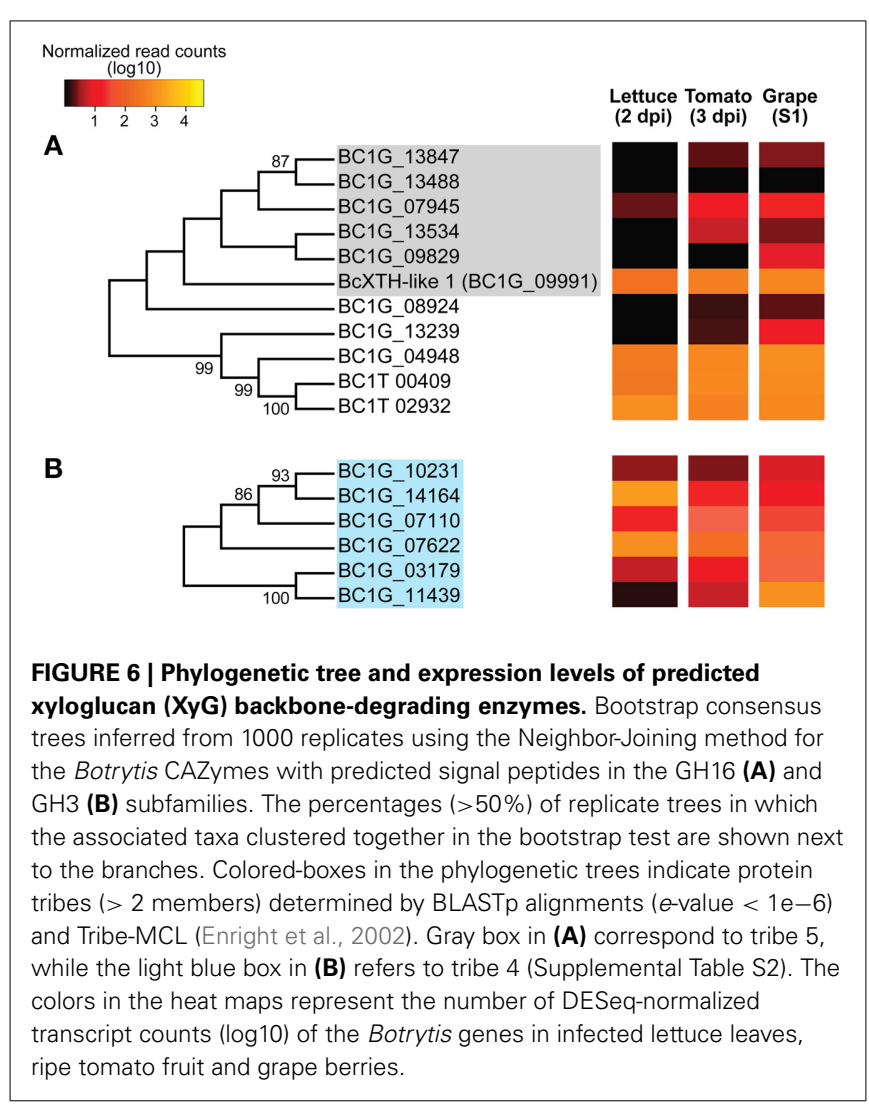

\section{DISCUSSION \\ BOTRYTIS EXPRESSES A LARGE AND DIVERSE SET OF ENZYMES TO DEGRADE PLANT CELL WALLS}

The presence and expression of specific CAZymes or gene families in plant pathogenic fungi have revealed the preferences of pathogens for particular host cell wall polysaccharides and infection strategies that are adapted to the pathogen lifestyle (King et al., 2011; Zhao et al., 2014). Our results indicate that Botrytis, a necrotroph, expressed most (>99\%) of its 1155 CAZyme genes during infections of lettuce leaves, ripe tomato fruit and grape berries, indicating that expression of a large and diverse array of cell wall-targeting proteins is an important hallmark of the necrotrophic lifestyle.

Botrytis, as a generalist pathogen, infects a wide variety of host tissues with different cell wall compositions and architectures. Therefore, identifying enzymes that Botrytis produces on different hosts, can help to define parts of the host cell wall polysaccharide matrix that are important targets for Botrytis growth or metabolism. A common set of 229 CAZyme genes with secretion signals was expressed by Botrytis when infecting the three different hosts. Eighty-two of these proteins were also detected in proteomic studies of the Botrytis secretome (Shah et al., 2009a,b; Espino et al., 2010; Fernández-Acero et al., 2010; Li et al., 2012; Shah et al., 2012).

These common CAZymes probably constitute the core enzymatic machinery utilized by Botrytis as it penetrates and invades various plant tissues. Pectin-degrading enzymes (e.g., characterized endo-PGs, putative RGases and candidate exo-PGs) were

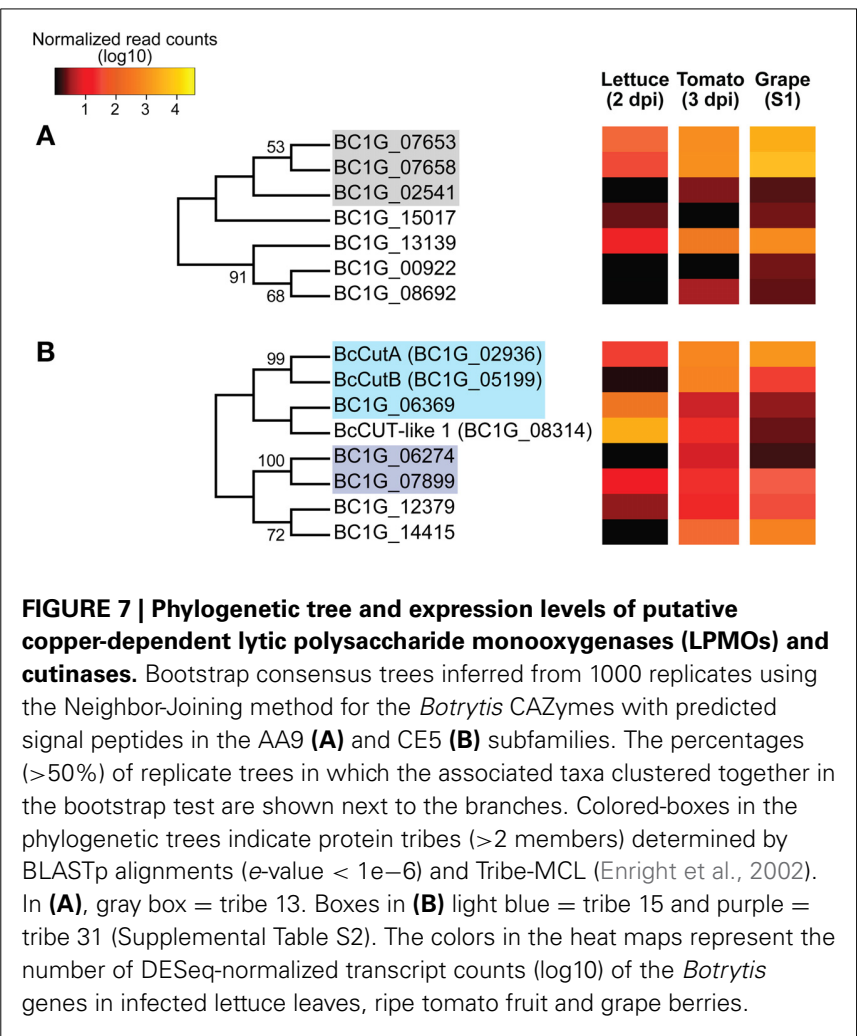

the most abundant plant cell wall modifying proteins among the CAZymes expressed in all hosts. This result confirms that pectin degradation is a key process during Botrytis infections of plant tissues, including those with higher proportions of cellulose and hemicellulose polysaccharides, such as lettuce leaves (Nunan et al., 1998; Wagstaff et al., 2010; Lunn et al., 2013).

Botrytis adapts its infection strategy to the diverse conditions present in the host cell walls. The expression of 43 Botrytis genes encoding predicted secreted CAZymes was detected in some but not all plant hosts. The majority $(83.72 \%)$ of these genes were commonly expressed in tomato and grape tissues, but not in lettuce leaves. Among these fruit-specific genes, those encoding putative xyloglucan $(\mathrm{XyG})$ transglucosylase/hydrolases and glucanases were the most abundant. A candidate exo-PG (BC1G_13137) gene that is only detected when in Botrytisinfected fruit had been detected when this pathogen was grown in minimal medium supplemented with pectins as the sole carbon source, which suggests that this enzyme is important in the degradation of host cell walls that are rich in pectins (Shah et al., 2009a). The molecules or signals lead to the expression of hostspecific enzymes are not known, but some could result from the degradation of host cell walls by core CAZymes (e.g., pectin derived oligosaccharides; Körner et al., 1998; An et al., 2005).

Botrytis may promote susceptibility in the host tissues by inducing or suppressing the expression of plant cell wall degrading enzymes (AbuQamar et al., 2006; Flors et al., 2007; Cantu et al., 2008b, 2009a). Fungal and plant enzymes may cooperate to effectively digest relatively complex polysaccharides. In addition, the activity of plant enzymes can result in the disassembly of the 
host cell walls beyond the site of fungal infection, which would facilitate the subsequent growth of Botrytis into the host tissues.

\section{PECTIN MODIFYING ENZYMES}

Botrytis produces a large collection of enzymes to degrade the backbones and side-branches of pectin polysaccharides. Breakdown of pectins during infections increases the plant cell wall's porosity, and may facilitate the degradation of other wall polysaccharides and the growth of Botrytis. Enzymes that target pectin backbones include PGs and RGases (GH28 subfamily), and PLs/PELs (PL1 and PL3 subfamilies). PMEs (CE8 subfamily) and RG esterases (CE12 subfamily) might cooperate in the effective degradation of pectin backbones (Van Kan, 2006; Zhang and van Kan, 2013a).

PGs hydrolyze the backbones of HGs. The Botrytis genome encodes 11 potentially secreted PGs, of which at least five are likely exo-PGs (i.e., predicted to remove sugar monomers from the non-reducing ends of $\mathrm{HG}$ or oligomeric products generated by endo-PG action on $\mathrm{HG}$ ) and six are endo-PGs (i.e., hydrolyze the HG polymer at internal sites). When infecting lettuce leaves and ripe fruit, Botrytis expressed four exo-PG and five endoPG genes (Table 2). BcPG2 was not detected in botrytized grape berries. The expression of $B c P G 2$ was up-regulated in the presence of pectate as carbon source in a host-free transcriptomics analysis (Zhang et al., 2013). The BcPG2 protein was detected at high levels when Botrytis was grown in media enriched with partially esterified pectin, glucose and extracts of tomato fruit, while only small quantities of BcPG2 protein were observed in Botrytis cultures supplemented with highly esterified pectin substrates or kiwi fruit extracts (Shah et al., 2009a; Espino et al., 2010). Taken together, these results indicate that the expression of $B c P G 2$ is differentially regulated depending on the conditions present in the plant host's cell wall matrixes (e.g., esterification status of the pectin polysaccharides; presence of inhibitors or activators of $B c P G 2$ gene expression, availability of particular cell wall substrates, efficiency of other BcPGs in a particular tissue).

In agreement with previous reports, $B c P G 1$ was the most highly expressed CAZyme gene in lettuce leaves, ripe tomato fruit and grape fruit (Reignault et al., 2000; Wubben et al., 2000; Ten Have et al., 2001). Although BcPG1 is not indispensable for virulence, the $\Delta b c p g 1$ knockout mutant is significantly less virulent in diverse hosts (Ten Have et al., 1998; Zhang and van Kan, 2013b). The expression data in this study support the conclusion that PGs, especially BcPG1, have major roles for Botrytis infections in a broad-range of plant tissues (Ten Have et al., 1998, 2001; Powell et al., 2000; Kars et al., 2005a; Rowe and Kliebenstein, 2007; Zhang et al., 2014).

Plants produce PG inhibiting proteins, PGIPs, to reduce the extensive pectin degradation caused by fungal, bacterial or insect attack (De Lorenzo et al., 2001). PGIPs inhibit most of the Botrytis's PGs (Sharrock and Labavitch, 1994; Joubert et al., 2007). Over-expression of PGIPs has been proven to increase the abundance of this inhibitor in the cell wall matrix and to reduce Botrytis growth on vegetative tissues and ripe tomato fruit (Powell et al., 2000; Ferrari et al., 2003, 2006).

In addition to the production of its own endo-PGs, Botrytis can trigger the expression of plant genes encoding endo-PGs.
Because plant endo-PGs are not inhibited by PGIPs (Cervone et al., 1990), they may assist in the breakdown of host cell wall pectins even when inhibitors of fungal enzymes are present. The tomato endo-PG, SlPG2A, is precociously up-regulated by Botrytis infections of unripe tomato fruit (Cantu et al., 2009a; Shah et al., 2012). The SIPG2A is considered a key cell wall degrading enzyme during tomato fruit ripening and softening (Bennett and Labavitch, 2008; Cantu et al., 2008b), and thus, its premature induction may benefit Botrytis infections.

PLs and PELs degrade HGs by a $\beta$-elimination rather than by hydrolysis. PLs generally act on heavily methylesterified HG backbones, and PELs are more efficient on lightly methylesterified HGs. Four PLs and four genes encoding PELs were annotated in the Botrytis genome, and the expression of all was detected in the three hosts (Table 2). However, the expression of these genes was lower than the expression of the $B c P G$ genes, suggesting that Botrytis PLs/PELs assist PGs and are not the primary enzymes attacking HGs.

The extent of methylation and acetylation of the HG backbones can impact the activity of Botrytis endo-PGs and PELs (Kars et al., 2005a). PMEs catalyze the specific demethylesterification of HGs. Three putative secreted PMEs are present in the Botrytis genome (BCPME1-3; Kars et al., 2005b). Although these three PMEs were expressed in Botrytis-infected lettuce leaves, tomato fruit, and grape berries, Botrytis PME activity seems not to be essential for virulence on certain hosts. Knockout mutations in $B c P M E 1$ and BcPME2 did not affect Botrytis's virulence on leaves of tomato and grapevine and on pear fruit (Kars et al., 2005b). However, BcPME1 was necessary for successful infections of apple fruit (Valette-Collet et al., 2003). It is possible that Botrytis relies on plant PMEs for demethylesterification of the HG backbones in certain host tissues (Raiola et al., 2011), or that the activity of BcPME3 can compensate for the absence of BcPME1 and BcPME2 (Kars et al., 2005b).

Plant PMEs may act as susceptibility factors by cooperating with Botrytis PMEs for the demethylesterification of HG backbones (Lionetti et al., 2012). For example, infection of Arabidopsis leaves by Botrytis alters the expression of host PME genes (AbuQamar et al., 2006), and the enhanced gene expression and activity of AtPME3 increases susceptibility to Botrytis (Raiola et al., 2011). In an effort to counteract the increased PME activity that results from encounters with pathogens, plants produce PME inhibitors (PMEIs; An et al., 2008; Volpi et al., 2011; Lionetti et al., 2012 , 2014). In vegetative tissues, the over-expression of plant PMEIs had been effective for limiting Botrytis infections Lionetti et al., 2007, 2012.

The Botrytis genome includes six possible secreted RGases, two $\alpha$-L-rhamnosidases and an RG acetylesterase (Table 2), which could cleave or modify RG-I backbones (Schols et al., 1994; Mutter et al., 1998; Mølgaard et al., 2000). Although expression of most of these genes was detected in the Botrytis-infected tissues, the low level of their expression may reflect the paucity of RG-I compared to HG pectins. RG-I is a major part of the hairy region of pectins in plant cell walls, but they are not as abundant as pectins with HG-backbones (Voragen et al., 2009).

Botrytis expressed diverse enzymes that are predicted to degrade pectin side-branches. Among these genes were four 
$\alpha$-arabinofuranosidases, three $\beta$-galactosidases, and two $\alpha$-L-1,5arabinanases (including BcAra1; Table 2). BcAral has been shown to degrade 1,5-arabinan in vitro. On Arabidopsis leaves but not tobacco or tomato leaves, the $\Delta$ bcaral knockout mutant has reduced virulence (Nafisi et al., 2014).

\section{HEMICELLULOSE MODIFYING ENZYMES}

A variety of hemicellulose-modifying enzymes is encoded in the Botrytis's genome. XyG backbones are hydrolyzed by endo-acting $\beta$-1,4-glucanases or $\beta$-glucosidases, which also act on cellulose (Gilbert, 2010). All of the predicted Botrytis $\beta$-glucosidase genes were expressed in infected lettuce leaves, tomato fruit and grape berries; however, expression levels of some were higher on lettuce leaves (Supplemental Table S2). The $\beta$-glucosidases were among the most numerous glycosyl hydrolases in fungal genomes (Zhao et al., 2014). XTHs can act on XyG backbones. They have two possible catalytic activities: (1) XyG endo-transglucosylase (XET) activity, which results in the non-hydrolytic cleavage and ligation of XyG polymers, and (2) XyG endo-hydrolase (XEH) activity that leads to the irreversible shortening of the XyG backbone (Eklöf and Brumer, 2010). The Botrytis genome has six candidate XTHs (GH16 subfamily), and two of this genes (BcXTH-like1 and BC1G_07945) were commonly expressed at low levels in all of the host tissues studied.

Xylans and mannans are present in the primary and secondary walls of many of Botrytis's hosts, but they are less abundant than XyGs. Digestion of these hemicelluloses may be important for Botrytis's energy acquisition and tissue exploration efforts. Expression of four $\beta$-xylanases (including BcXyn11A; Table 2) and two $\beta$-xylosidases $\left(B C 1 G \_02487\right.$ and $\left.B C 1 G \_10797\right)$, which target xylan backbones, is detected when Botrytis infects lettuce leaves, ripe tomato fruit and post-véraison grape berries. Deletion of the BcXyn11A gene delayed disease symptoms and reduced the lesion size on tomato leaves and table grape berries (Brito et al., 2006). However, the contribution of BcXyn11A to overall virulence does not depend on its xylanase activity; rather, it is related to the necrosis in the host caused by the xylanase protein itself (Noda et al., 2010).

Some of the side-branches along the XyG and xylan backbones contribute to the overall strength of the hemicellulose-cellulose microfibril network (Pauly et al., 2013). Therefore, removal of these groups might affect the hemicellulose cross-linking properties and, at least locally, disrupt the wall's hemicellulosecellulose network. In all hosts analyzed, Botrytis expressed two $\alpha$-xylosidases $\left(B C 1 G \_12859\right.$ and $\left.B C 1 G \_11115\right)$ and one $\alpha$-Lfucosidase (BC1G_08975). These enzymes could digest XyG side groups, exposing the hemicellulose's glucan backbone to further digestion. Additional enzymes that remove side-branches in hemicelluloses may be the same as or functionally equivalent to CAZymes that trim the side groups of pectins; e.g., $\alpha$-arabinofuranosidases (previously described).

\section{CELLULOSE MODIFYING ENZYMES}

Botrytis expresses genes encoding predicted cellulose-degrading enzymes; these include nine endo- $\beta$-1,4-glucanases (including $B c C e l 5 A$ ), five cellobiohydrolases, and the previously discussed $\beta$-glucosidases. Espino et al. (2005) demonstrated that a mutant with a deletion in $B c C e l 5 A$ (BC1G_00642), an endo- $\beta$ 1,4-glucanase encoding gene, can infect tomato leaves and gerbera petals. Because the expression of $B c C e l 5 A$ appears to be relevant during spore germination and penetration of waxy surfaces (Leroch et al., 2013), evaluating the virulence of $\Delta b c c e l 5 a$ mutants in these hosts may provide information about the importance of this enzyme during infections.

As consequence of Botrytis infection, expression of plant endo$\beta$-1,4-glucanases is reduced (Flors et al., 2007; Finiti et al., 2013). Transgenic suppression of endo- $\beta$-1,4-glucanases limited Botrytis growth and promoted the activation of defense responses in tomato fruit and Arabidopsis and tomato leaf tissues. These responses included enhanced callose deposition and expression of defense genes, e.g., PR1 and LoxD (Flors et al., 2007; Finiti et al., 2013).

Copper-dependent lytic polysaccharide monooxygenases (LPMOs) cooperate with canonical cellulose-degrading enzymes and other electron transfer proteins to accelerate the degradation of cellulose microfibrils (Hemsworth et al., 2013). A number of LPMOs have been identified mainly in fungal genomes, especially in wood decay-causing fungi (Levasseur et al., 2013). Botrytis expressed two putative LPMOs (BC1G_07653 and BC1G_08692) in lettuce leaves and fruit hosts. However, a larger number of LPMOs was expressed during infections of ripe fruit (especially grape tissues) and their expression was higher than in the other plant host tissues (Supplemental Table S2).

\section{CUTINASES}

In the absence of cracks or wounds in the plant surface, the initial interactions between a host and Botrytis occur at the plant cuticle. In those situations, Botrytis secretes an assortment of cutinases and lipases to breach the cuticle and penetrate the host (Van Kan et al., 1997; Reis et al., 2005; Van Kan, 2006; Leroch et al., 2013). Cutinases cleave ester bonds between cutin monomers (Pio and Macedo, 2009).

When infecting the three hosts analyzed, Botrytis expressed $B c C u t A$ and three other putative cutinases (BcCutB, BcCUTlike1 and BC1G_06369). The expression levels of these enzymes depended on the host tissues; for example, $B c C u t A$ was highly expressed in fruit, but not in lettuce leaves. The expression of $B c C u t A$ was up-regulated during early germination of Botrytis spores on apple wax; this may indicate that $B c C u t A$ may be preferentially expressed at the surfaces of fleshy fruit, where wax accumulation is common (Leroch et al., 2013). Some Botrytis cutinases showed high homology to acetylxylan esterases, which are associated with the degradation of xylans. The Botrytis genome encodes two putative acetylxylan esterases (BC1G_12379 and BC1G_07899), and one was expressed in all infected plant tissues analyzed. Results in Skamnioti et al. (2008) suggested that the functional diversification between cutinases and acetylxylan esterases may have occurred before the speciation of Botrytis cinerea and two other ascomycete pathogens, Fusarium graminearum and Neurospora crassa.

\section{CONCLUDING REMARKS}

The diversity of CAZyme-encoding genes in the Botrytis genome and their extensive expression when this necrotroph interacts 
with its hosts suggests that the pathogen's ability to degrade a wide-range of cell wall polysaccharides is tightly associated with its success in infecting a broad range of plant hosts. While several proteins were previously identified by proteomic analyses, this study expands the catalog of the complex array of enzymes that Botrytis may secrete to digest host tissues. Pectins, particularly pectin backbones, appear to be the main target of degradation by Botrytis in leaf and fruit tissues. However, Botrytis also expresses particular CAZyme genes only when infecting certain hosts. What promotes this host-specific expression of CAZyme genes is not known. Information about the structural details of the associations between the constituents of diverse host plant cell walls is needed to fully understand how Botrytis benefits from the digestion of plant cell wall polysaccharides during successful infections. In addition, understanding plant responses to Botrytis infections, which may include altered expression of endogenous CAZyme genes (Flors et al., 2007; Cantu et al., 2008b, 2009a) or inhibitors of cell wall degrading enzymes (De Lorenzo et al., 1994; Powell et al., 2000; De Lorenzo and Ferrari, 2002; Lionetti et al., 2007, 2014) and plant cell wall fortifications (Van Baarlen et al., 2007; Finiti et al., 2013), may shed some light on the co-evolution of plant and pathogen strategies and their impact on resistance or susceptibility to fungal infections.

Measurements of enzymatic activity in vitro as well as in planta on cell wall polysaccharides may confirm the predicted enzymatic activities of some of the genes described in this study. This information may refine our understanding of important virulence functions needed for successful Botrytis infections. Another strategy to demonstrate that cell wall modifications have occurred during Botrytis infection would be to identify the accumulation of characteristic breakdown products; e.g., pectin derived oligosaccharides that result from the activity of PLs and PGs (Melotto et al., 1994; Körner et al., 1998; An et al., 2005). Validation of the role and function of the Botrytis cell wall modifying enzymes may also be achieved by targeted mutagenesis, with the caveat that it is expected that most of these enzymes have paralogs with redundant activities and/or their functions may depend on other proteins, including some produced by the plant host.

\section{ACKNOWLEDGMENTS}

This work was partially supported by funding to Dario Cantu from the College of Agricultural and Environmental Sciences and the Department of Viticulture and Enology (UC Davis) and to Ann L. T. Powell from NSF (IOS 0957264). Support to Barbara Blanco-Ulate was provided by the Consejo Nacional de Ciencia y Tecnología (Ministerio de Ciencia y Tecnología, Costa Rica) and by the Department of Plant Sciences (UC Davis).

\section{SUPPLEMENTARY MATERIAL}

The Supplementary Material for this article can be found online at: http://www.frontiersin.org/journal/10.3389/fpls.2014.00435/ abstract

\section{REFERENCES}

AbuQamar, S., Chen, X., Dhawan, R., Bluhm, B., Salmeron, J., Lam, S., et al. (2006). Expression profiling and mutant analysis reveals complex regulatory networks involved in Arabidopsis response to Botrytis infection. Plant J. 48, 28-44. doi: 10.1111/j.1365-313X.2006.02849.x

Amselem, J., Cuomo, C. A., van Kan, J. A. L., Viaud, M., Benito, E. P., Couloux, A., et al. (2011). Genomic analysis of the necrotrophic fungal pathogens Sclerotinia sclerotiorum and Botrytis cinerea. PLoS Genet. 7:e1002230. doi: 10.1371/journal.pgen.1002230

An, H. J., Lurie, S., Greve, L. C., Rosenquist, D., Kirmiz, C., Labavitch, J. M., et al. (2005). Determination of pathogen-related enzyme action by mass spectrometry analysis of pectin breakdown products of plant cell walls. Anal. Biochem. 338, 71-82. doi: 10.1016/j.ab.2004.11.004

An, S. H., Sohn, K. H., Choi, H. W., Hwang, I. S., Lee, S. C., and Hwang, B. K. (2008). Pepper pectin methylesterase inhibitor protein CaPMEI1 is required for antifungal activity, basal disease resistance and abiotic stress tolerance. Planta 228, 61-78. doi: 10.1007/s00425-008-0719-z

Anders, S., and Huber, W. (2010). Differential expression analysis for sequence count data. Genome Biol. 11:R106. doi: 10.1186/gb-2010-11-10-r106

Bennett, A. B., and Labavitch, J. M. (2008). Ethylene and ripening-regulated expression and function of fruit cell wall modifying proteins. Plant Sci. 175, 130-136. doi: 10.1016/j.plantsci.2008.03.004

Blanco-Ulate, B., Rolshausen, P. E., and Cantu, D. (2013a). Draft genome sequence of Botrytis cinerea $\mathrm{BcDW} 1$, inoculum for noble rot of grape berries. Genome Announc. 1:e00252-13. doi: 10.1128/genomeA.00252-13

Blanco-Ulate, B., Rolshausen, P. E., and Cantu, D. (2013b). Draft genome sequence of Neofusicoccum parvum isolate UCR-NP2, a fungal vascular pathogen associated with grapevine cankers. Genome Announc. 1:e00339-13. doi: 10.1128/genomeA.00339-13

Blanco-Ulate, B., Rolshausen, P. E., and Cantu, D. (2013c). Draft genome sequence of the ascomycete Phaeoacremonium aleophilum strain UCR-PA7, a causal agent of the Esca disease complex in grapevines. Genome Announc. 1:e00390-13. doi: 10.1128/genomeA.00390-13

Blanco-Ulate, B., Rolshausen, P. E., and Cantu, D. (2013d). Draft genome sequence of the grapevine dieback fungus Eutypa lata UCR-EL1. Genome Announc. 1:e00228-13. doi: 10.1128/genomeA.00228-13

Blanco-Ulate, B., Vincenti, E., Powell, A. L. T., and Cantu, D. (2013e). Tomato transcriptome and mutant analyses suggest a role for plant stress hormones in the interaction between fruit and Botrytis cinerea. Front. Plant Sci. 4:142. doi: 10.3389/fpls.2013.00142

Brito, N., Espino, J., and González, C. (2006). The endo- $\beta$-1,4-xylanase Xyn11A is required for virulence in Botrytis cinerea. Mol. Plant Microbe Interact. 19, 25-32. doi: 10.1094/MPMI-19-0025

Cantarel, B. L., Coutinho, P. M., Rancurel, C., Bernard, T., Lombard, V., and Henrissat, B. (2009). The Carbohydrate-Active EnZymes database (CAZy): an expert resource for glycogenomics. Nucleic Acids Res. 37, 233-238. doi: $10.1093 / \mathrm{nar} / \mathrm{gkn} 663$

Cantu, D., Blanco-Ulate, B., Yang, L., Labavitch, J. M., Bennett, A. B., and Powell, A. L. T. (2009a). Ripening-regulated susceptibility of tomato fruit to Botrytis cinerea requires NOR but not RIN or ethylene. Plant Physiol. 150, 1434-1449. doi: 10.1104/pp.109.138701

Cantu, D., Greve, L. C., Labavitch, J. M., and Powell, A. L. T. (2009b). Characterization of the cell wall of the ubiquitous plant pathogen Botrytis cinerea. Mycol. Res. 113, 1396-1403. doi: 10.1016/j.mycres.2009.09.006

Cantu, D., Segovia, V., MacLean, D., Bayles, R., Chen, X., Kamoun, S., et al. (2013). Genome analyses of the wheat yellow (stripe) rust pathogen Puccinia striiformis f. sp. tritici reveal polymorphic and haustorial expressed secreted proteins as candidate effectors. BMC Genomics 14:270. doi: 10.1186/1471-216414-270

Cantu, D., Vicente, A., Greve, L., Dewey, F., Bennett, A., Labavitch, J., et al. (2008b). The intersection between cell wall disassembly, ripening and fruit susceptibility to Botrytis cinerea. Proc. Natl. Acad. Sci. U.S.A. 105, 859-864. doi: 10.1073/pnas.0709813105

Cantu, D., Vicente, A. R., Labavitch, J. M., Bennett, A. B., and Powell, A. L. T. (2008a). Strangers in the matrix: plant cell walls and pathogen susceptibility. Trends Plant Sci. 13, 610-617. doi: 10.1016/j.tplants.2008.09.002.

Carpita, N. C., and Gibeaut, D. M. (1993). Structural models of primary cell walls in flowering plants: consistency of molecular structure with the physical properties of the walls during growth. Plant J. 3, 1-30. doi: 10.1111/j.1365313X.1993.tb00007.x

Cassab, G. I. (1998). Plant cell wall proteins. Annu. Rev. Plant Physiol. Plant Mol.Biol. 49, 281-309. doi: 10.1146/annurev.arplant.49.1.281 
Cervone, F., De Lorenzo, G., Pressey, R., Darvill, A. G., and Albersheim, P. (1990). Can Phaseolus PGIP inhibit pectic enzymes from microbes and plants? Phytochem. 29, 447-449. doi: 10.1016/0031-9422(90)85094-V

Chen, A., and Dubcovsky, J. (2012). Wheat TILLING mutants show that the vernalization gene VRN1 down-regulates the flowering repressor VRN2 in leaves but is not essential for flowering. PLoS Genetics 8:e1003134. doi: 10.1371/journal.pgen.1003134

Curvers, K., Seifi, H., Mouille, G. D., Rycke, R., Asselbergh, B., Van Hecke, A., et al. (2010). ABA-deficiency causes changes in cuticle permeability and pectin composition that influence tomato resistance to Botrytis cinerea. Plant Physiol. 154, 847-860. doi: 10.1104/pp.110.158972

De Cremer, K., Mathys, J., Vos, C., Froenicke, L., Michelmore, R. W., Cammue, B. P. A., et al. (2013). RNAseq-based transcriptome analysis of Lactuca sativa infected by the fungal necrotroph Botrytis cinerea. Plant Cell Environ. 36, 1992-2007. doi: $10.1111 /$ pce. 12106

De Lorenzo, G., Cervone, F., Bellincampi, D., Caprari, C., Clark, A. J., Desiderie, A., et al. (1994). Polygalacturonase, PGIP and oligogalacturonides in cell-cell communication. Biochem. Soc. Trans. 22, 394-397.

De Lorenzo, G., D'Ovidio, R., and Cervone, F. (2001). The role of polygalacturonase-inhibiting proteins (PGIPs) in defense against pathogenic fungi. Annu. Rev. Phytopathol. 39, 313-335. doi: 10.1146/annurev.phyto. 39.1.313

De Lorenzo, G., and Ferrari, S. (2002). Polygalacturonase-inhibiting proteins in defense against phytopathogenic fungi. Curr. Opin. Plant Biol. 5, 295-299. doi: 10.1016/S1369-5266(02)00271-6

Edgar, R. C. (2004). MUSCLE: multiple sequence alignment with high accuracy and high throughput. Nucleic Acids Res. 32, 1792-1797. doi: 10.1093/nar/gkh340

Eklöf, J. M., and Brumer, H. (2010). The XTH gene family: an update on enzyme structure, function, and phylogeny in xyloglucan remodeling. Plant Physiol. 153, 456-466. doi: 10.1104/pp.110.156844

Enright, A. J., Kunin, V., and Ouzounis, C. A. (2003). Protein families and TRIBES in genome sequence space. Nucleic Acids Res. 31, 4632-4638. doi: 10.1093/nar/gkg495

Enright, A. J., Van Dongen, S., and Ouzounis, C. A. (2002). An efficient algorithm for large-scale detection of protein families. Nucleic Acids Res. 30, 1575-1584. doi: 10.1093/nar/30.7.1575

Espino, J., Brito, N., Noda, J., and Gonzalez, C. (2005). Botrytis cinerea endo-ß-1, 4glucanase Cel5A is expressed during infection but is not required for pathogenesis. Physiol. Mol. Plant Pathol. 66, 213-221. doi: 10.1016/j.pmpp.2005.06.005

Espino, J., Gutiérrez-Sánchez, G., Brito, N., Shah, P., Orlando, R., and González, C. (2010). The Botrytis cinerea early secretome. Proteomics 10, 3020-3034. doi: $10.1002 /$ pmic. 201000037

Faure, D. (2002). The family-3 glycoside hydrolases: from housekeeping functions to host-microbe interactions. Appl. Environ. Microbiol. 68, 1485-1490. doi: 10.1128/AEM.68.4.1485-1490.2002

Felsenstein, J. (1985). Confidence limits on phylogenies: an approach using the bootstrap. Evolution 39, 783-791. doi: 10.2307/2408678

Fernández-Acero, F. J., Colby, T., Harzen, A., Carbú, M., Wieneke, U., Cantoral, J. M., et al. (2010). 2-DE proteomic approach to the Botrytis cinerea secretome induced with different carbon sources and plant-based elicitors. Proteomics 10, 2270-2280. doi: 10.1002/pmic.200900408

Ferrari, S., Galletti, R., Vairo, D., Cervone, F., and De Lorenzo, G. (2006). Antisense expression of the Arabidopsis thaliana AtPGIP1 gene reduces polygalacturonaseinhibiting protein accumulation and enhances susceptibility to Botrytis cinerea. Mol. Plant Microbe Interact. 19, 931-936. doi: 10.1094/MPMI-19-0931

Ferrari, S., Vairo, D., Ausubel, F. M., Cervone, F., and De Lorenzo, G. (2003). Tandemly duplicated Arabidopsis genes that encode polygalacturonaseinhibiting proteins are regulated coordinately by different signal transduction pathways in response to fungal infection. Plant Cell 15, 93-106. doi: 10.1105/tpc.005165

Finiti, I., Leyva, M., López-Cruz, J., Calderan Rodrigues, B., Vicedo, B., Angulo, C., et al. (2013). Functional analysis of endo-1, 4- $\beta$-glucanases in response to Botrytis cinerea and Pseudomonas syringae reveals their involvement in plant-pathogen interactions. Plant Biol. 15, 819-831. doi: 10.1111/j.14388677.2012.00701.x

Flors, V., Leyva, M., Vicedo, B., Finiti, I., Real, M. D., Garcia-Agustin, P., et al. (2007). Absence of the endo- $\beta$-1, 4-glucanses Cel1 and Cel2 reduces susceptibility to Botrytis cinerea in tomato. Plant J. 52, 1027-1040. doi: 10.1111/j.1365313X.2007.03299.x
Floudas, D., Binder, M., Riley, R., Barry, K., Blanchette, R. A., Henrissat, B., et al. (2012). The paleozoic origin of enzymatic lignin decomposition reconstructed from 31 fungal genomes. Science 336, 1715-1719. doi: 10.1126/science.1221748

Gilbert, H. J. (2010). The biochemistry and structural biology of plant cell wall deconstruction. Plant Physiol. 153, 444-455. doi: 10.1104/pp.110.156646

Götz, S., García-Gómez, J. M., Terol, J., Williams, T. D., Nagaraj, S. H., Nueda, M. J., et al. (2008). High-throughput functional annotation and data mining with the Blast2GO suite. Nucleic Acids Res. 36, 3420-3435. doi: 10.1093/nar/ gkn176

Haas, B. J., Kamoun, S., Zody, M. C., Jiang, R. H. Y., Handsaker, R. E., Cano, L. M., et al. (2009). Genome sequence and analysis of the Irish potato famine pathogen Phytophthora infestans. Nature 461, 393-398. doi: 10.1038/nature08358

Harris, P. J., and Stone, B. A. (2008). "Chemistry and molecular organization of plant cell walls," in Biomass Recalcitrance: Deconstructing the Plant Cell Wall for Bioenergy, ed M. E. Himmel (London, UK: Blackwell Publishing), 61-93.

Hematy, K., Cherk, C., and Somerville, S. (2009). Host-pathogen warfare at the plant cell wall. Curr. Opin. Plant Biol. 12, 406-413. doi: 10.1016/j.pbi.2009.06.007

Hemsworth, G. R., Davies, G. J., and Walton, P. H. (2013). Recent insights into copper-containing lytic polysaccharide mono-oxygenases. Curr. Opin. Struc. Biol. 23, 660-668. doi: 10.1016/j.sbi.2013.05.006

Ishii, T., Matsunaga, T., and Hayashi, N. (2001). Formation of rhamnogalacturonan II-borate dimer in pectin determines cell wall thickness of pumpkin tissue. Plant Physiol. 126, 1698-1705. doi: 10.1104/pp.126.4.1698

Ithal, N., Recknor, J., Nettleton, D., Hearne, L., Maier, T., Baum, T. J., et al. (2007). Parallel genome-wide expression profiling of host and pathogen during soybean cyst nematode infection of soybean. Mol. Plant Microbe Interact. 20, 293-305. doi: 10.1094/MPMI-20-3-0293

Jayani, R. S., Saxena, S., and Gupta, R. (2005). Microbial pectinolytic enzymes: a review. Process Biochem. 40, 2931-2944. doi: 10.1016/j.procbio.2005.03.026

Jeon, J., Park, S. Y., Chi, M. H., Choi, J., Park, J., Rho, H. S., et al. (2007). Genomewide functional analysis of pathogenicity genes in the rice blast fungus. Nat. Genet. 39, 561-565. doi: 10.1038/ng2002

Joubert, D. A., Kars, I., Wagemakers, L., Bergmann, C., Kemp, G., Vivier, M. A., et al. (2007). A polygalacturonase-inhibiting protein from grapevine reduces the symptoms of the endopolygalacturonase $\mathrm{BcPG} 2$ from Botrytis cinerea in Nicotiana benthamiana leaves without any evidence for in vitro interaction. Mol. Plant Microbe Interact. 20, 392-402. doi: 10.1094/MPMI-20-4-0392

Kars, I., Krooshof, G. H., Wagemakers, L., Joosten, R., Benen, J. A. E., and van Kan, J. A. L. (2005a). Necrotizing activity of five Botrytis cinerea endopolygalacturonases produced in Pichia pastoris. Plant J. 43, 213-225. doi: 10.1111/j.1365313X.2005.02436.x

Kars, I., McCalman, M., Wagemakers, L., and van Kan, J. A. L. (2005b). Functional analysis of Botrytis cinerea pectin methlesterase genes by PCR-based targeted mutagenesis: Bcpme1 and Bcpme2 are dispensable for virulence of strain B05.10. Mol. Plant Pathol. 6, 641-652. doi: 10.1111/j.1364-3703.2005.00312.x

Keegstra, K. (2010). Plant cell walls. Plant Physiol. 154, 483-486. doi: 10.1104/pp.110.161240

King, B. C., Waxman, K. D., Nenni, N. V., Walker, L. P., Bergstrom, G. C., and Gibson, D. M. (2011). Arsenal of plant cell wall degrading enzymes reflects host preference among plant pathogenic fungi. Biotechnol. Biofuels 4:4. doi: 10.1186/1754-6834-4-4

Klis, F. M., Brul, S., and De Groot, P. W. J. (2010). Covalently linked wall proteins in ascomycetous fungi. Yeast 27, 489-493. doi: 10.1002/yea.1747

Körner, R., Limberg, G., Mikkelsen, J. D., and Roepstorff, P. (1998). Characterization of enzymatic pectin digests by matrix-assisted laser desorption/ionization mass spectrometry. J. Mass Spectrom. 33, 836-842.

Langmead, B., and Salzberg, S. L. (2012). Fast gapped-read alignment with Bowtie 2. Nat. Methods 9, 357-359. doi: 10.1038/nmeth.1923

Leroch, M., Kleber, A., Silva, E., Coenen, T., Koppenhofer, D., Shmaryahu, A., et al. (2013). Transcriptome profiling of Botrytis cinerea conidial germination reveals upregulation of infection-related genes during the prepenetration stage. Eukaryot. Cell 12, 614-626. doi: 10.1128/EC.00295-12

Levasseur, A., Drula, E., Lombard, V., Coutinho, P. M., and Henrissat, B. (2013). Expansion of the enzymatic repertoire of the CAZy database to integrate auxiliary redox enzymes. Biotechnol. Biofuels 6:41. doi: 10.1186/1754-68 34-6-41

Li, B., Wang, W., Zong, Y., Qin, G., and Tian, S. (2012). Exploring pathogenic mechanisms of Botrytis cinerea secretome under different ambient $\mathrm{pH}$ based 
on comparative proteomic analysis. J. Proteome Res. 11, 4249-4260. doi: $10.1021 / \mathrm{pr} 300365 \mathrm{f}$

Lionetti, V., Cervone, F., and Bellincampi, D. (2012). Methyl esterification of pectin plays a role during plant-pathogen interactions and affects plant resistance to diseases. J. Plant Physiol. 169, 1623-1630. doi: 10.1016/j.jplph.2012.05.006

Lionetti, V., Raiola, A., Cervone, F., and Bellincampi, D. (2014). Transgenic expression of pectin methylesterase inhibitors limits tobamovirus spread in tobacco and Arabidopsis. Mol. Plant Pathol. 15, 265-274. doi: 10.1111/mpp.12090

Lionetti, V., Raiola, A., Camardella, L., Giovane, A., Obel, N., Pauly, M., et al. (2007). Overexpression of pectin methylesterase inhibitors in Arabidopsis restricts fungal infection by Botrytis cinerea. Plant Physiol. 143, 1871-1880. doi: 10.1104/pp.106.090803

Lunn, D., Phan, T. D., Tucker, G. A., and Lycett, G. W. (2013). Cell wall composition of tomato fruit changes during development and inhibition of vesicle trafficking is associated with reduced pectin levels and reduced softening. Plant Physiol. Biochem. 66, 91-97. doi: 10.1016/j.plaphy.2013.02.005

Melhem, H., Min, X. J., and Butler, G. (2013). “The impact of SignalP 4.0 on the prediction of secreted proteins," in Computational Intelligence in Bioinformatics and Computational Biology (CIBCB), 2013 IEEE Symposium (Singapore), 16-22.

Melotto, E., Greve, L. C., and Labavitch, J. M. (1994). Cell wall metabolism in ripening fruit. VII. Biologically active pectin oligomers in ripening tomato (Lycopersicon esculentum Mill.) Fruits. Plant Physiol. 106, 575-581.

Meyer, U. M., and Dewey, F. M. (2000). Efficacy of different immunogens for raising monoclonal antibodies to Botrytis cinerea. Mycol. Res. 104, 979-987. doi: $10.1017 /$ S0953756200002501

Mohnen, D. (2008). Pectin structure and biosynthesis. Curr. Opin. Plant Biol. 11, 266-277. doi: 10.1016/j.pbi.2008.03.006

Mølgaard, A., Kauppinen, S., and Larsen, S. (2000). Rhamnogalacturonan acetylesterase elucidates the structure and function of a new family of hydrolases. Structure 8, 373-383. doi: 10.1016/S0969-2126(00)00118-0

Mutter, M., Renard, C. M., Beldman, G., Schols, H. A., and Voragen, A. G. (1998). Mode of action of RG-hydrolase and RG-lyase toward rhamnogalacturonan oligomers. Characterization of degradation products using RGrhamnohydrolase and RG-galacturonohydrolase. Carbohyd. Res. 311, 155-164. doi: 10.1016/S0008-6215(98)00188-8

Nafisi, M., Stranne, M., Zhang, L., van Kan, J., and Sakuragi, Y. (2014). The endoarabinanase BcAral is a novel host-specific virulence factor of the necrotic fungal phytopathogen Botrytis cinerea. Mol. Plant Microbe Interact. 27, 781-792. doi: 10.1094/MPMI-02-14-0036-R

Noda, J., Brito, N., and Gonzalez, C. (2010). The Botrytis cinerea xylanase Xyn11A contributes to virulence with its necrotizing activity, not with its catalytic activity. BMC Plant Biol. 10:38. doi: 10.1186/1471-2229-10-38

Noël, L., Thieme, F., Nennstiel, D., and Bonas, U. (2001). cDNA-AFLP analysis unravels a genome-wide hrpG-regulon in the plant pathogen Xanthomonas campestris pv. vesicatoria. Mol. Microbiol. 41, 1271-1281. doi: 10.1046/j.13652958.2001.02567.x

Nunan, K. J., Sims, I. M., Bacic, A., Robinson, S. P., and Fincher, G. B. (1998). Changes in cell wall composition during ripening of grape berries. Plant Physiol. 118, 783-792. doi: 10.1104/pp.118.3.783

O'Connell, R. J., Thon, M. R., Hacquard, S., Amyotte, S. G., Kleemann, J., Torres, M. F., et al. (2012). Lifestyle transitions in plant pathogenic Colletotrichum fungi deciphered by genome and transcriptome analyses. Nat. Genet. 44, 1060-1065. doi: 10.1038/ng.2372

Park, B. H., Karpinets, T. V., Syed, M. H., Leuze, M. R., and Uberbacher, E. C. (2010). CAZymes Analysis Toolkit (CAT): web service for searching and analyzing carbohydrate-active enzymes in a newly sequenced organism using CAZy database. Glycobiology 20, 1574-1584. doi: 10.1093/glycob/cwq106

Pauly, M., Gille, S., Liu, L., Mansoori, N., Souza, A., Schultink, A., et al. (2013). Hemicellulose biosynthesis. Planta 238, 627-642. doi: 10.1007/s00425-0131921-1

Petersen, T. N., Brunak, S., von Heijne, G., and Nielsen, H. (2011). SignalP 4.0: discriminating signal peptides from transmembrane regions. Nat. Methods 8, 785-786. doi: 10.1038/nmeth.1701

Pio, T. F., and Macedo, G. A. (2009). Cutinases: properties and industrial applications. Adv. Appl. Microbiol. 66, 77-95. doi: 10.1016/S0065-2164(08)00804-6

Powell, A. L. T., van Kan, J. A. L., ten Have, A., Visser, J., Greve, L. C., Bennett, A. B., et al. (2000). Transgenic expression of pear PGIP in tomato limits fungal colonization. Mol. Plant Microbe Interact. 13, 942-950. doi: 10.1094/MPMI.2000.13.9.942
Raiola, A., Lionetti, V., Elmaghraby, I., Immerzeel, P., Mellerowicz, E. J., Salvi, G., et al. (2011). Pectin methylesterase is induced in Arabidopsis upon infection and is necessary for a successful colonization by necrotrophic pathogens. Mol. Plant Microbe Interact. 24, 432-440. doi: 10.1094/MPMI-07-10-0157

Reignault, P., Kunz, C., Delage, N., Moreau, E., Vedel, R., Hamada, W., et al. (2000). Host-and symptom-specific pectinase isozymes produced by Botrytis cinerea. Mycol. Res. 104, 421-428. doi: 10.1017/S0953756299001501

Reis, H., Pfiffi, S., and Hahn, M. (2005). Molecular and functional characterization of a secreted lipase from Botrytis cinerea. Mol. Plant Pathol. 6, 257-267. doi: 10.1111/j.1364-3703.2005.00280.x

Rowe, H. C., and Kliebenstein, D. J. (2007). Elevated genetic variation within virulence-associated Botrytis cinerea polygalacturonase loci. Mol. Plant Microbe Interact. 20, 1126-1137. doi: 10.1094/MPMI-20-9-1126

Saitou, N., and Nei, M. (1987). The neighbor-joining method: a new method for reconstructing phylogenetic trees. Mol. Biol. Evol. 4, 406-425.

Scheller, H. V., and Ulvskov, P. (2010). Hemicelluloses. Annu. Rev. Plant Biol. 61, 263-289. doi: 10.1146/annurev-arplant-042809-112315

Schmidtke, C., Findeiss, S., Sharma, C. M., Kuhfuss, J., Hoffmann, S., Vogel, J., et al. (2012). Genome-wide transcriptome analysis of the plant pathogen Xanthomonas identifies sRNAs with putative virulence functions. Nucleic Acids Res. 40, 2020-2031. doi: 10.1093/nar/gkr904

Schols, H. A., Voragen, A. G., and Colquhoun, I. J. (1994). Isolation and characterization of rhamnogalacturonan oligomers, liberated during degradation of pectic hairy regions by rhamnogalacturonase. Carbohyd. Res. 256, 97-111. doi: 10.1016/0008-6215(94)84230-2

Shah, P., Atwood, J. A., Orlando, R., El Mubarek, H., Podila, G. K., and Davis, M. R. (2009b). Comparative proteomic analysis of Botrytis cinerea secretome. J. Proteome Res. 8, 1123-1130. doi: 10.1021/pr8003002

Shah, P., Gutierrez-Sanchez, G., Orlando, R., and Bergmann, C. (2009a). A proteomic study of pectin-degrading enzymes secreted by Botrytis cinerea grown in liquid culture. Proteomics 9, 3126-3135. doi: 10.1002/pmic.200800933

Shah, P., Powell, A. L., Orlando, R., Bergmann, C., and Gutierrez-Sanchez, G. (2012). Proteomic analysis of ripening tomato fruit infected by Botrytis cinerea. J. Proteome Res. 11, 2178-2192. doi: 10.1021/pr200965c

Sharrock, K. R., and Labavitch, J. M. (1994). Polygalacturonase inhibitors of Bartlett pear fruits: differential effects on Botrytis cinerea polygalacturonase isozymes, and influence on products of fungal hydrolysis of pear cell walls and on ethylene induction in cell culture. Physiol. Mol. Plant Pathol. 45, 305-319. doi: 10.1016/S0885-5765(05)80061-X

Skamnioti, P., Furlong, R. F., and Gurr, S. J. (2008). The fate of gene duplicates in the genomes of fungal pathogens. Commun. Integr. Biol. 1, 196-198. doi: 10.4161/cib.1.2.7144

Suzuki, H., MacDonald, J., Syed, K., Salamov, A., Hori, C., Aerts, A., et al. (2012). Comparative genomics of the white-rot fungi, Phanerochaete carnosa and $P$. chrysosporium, to elucidate the genetic basis of the distinct wood types they colonize. BMC Genomics 13:444. doi: 10.1186/1471-2164-13-444

Tamura, K., Peterson, D., Peterson, N., Stecher, G., Nei, M., and Kumar, S. (2011). MEGA5: molecular evolutionary genetics analysis using maximum likelihood, evolutionary distance, and maximum parsimony methods. Mol. Biol. Evol. 28, 2731-2739. doi: 10.1093/molbev/msr121

Ten Have, A., Breuil, W. O., Wubben, J. P., Visser, J., and van Kan, J. A. L. (2001). Botrytis cinerea endopolygalacturonase genes are differentially expressed in various plant tissues. Fungal Genet. Biol. 33, 97-105. doi: 10.1006/fgbi.2001.1269

Ten Have, A., Mulder, W., Visser, J., and van Kan, J. A. L. (1998). The endopolygalacturonase gene Bcpg1 is required for full virulence of Botrytis cinerea. Mol. Plant Microbe Interact. 11, 1009-1016.

Tiedemann, A. V. (1997). Evidence for a primary role of active oxygen species in induction of host cell death during infection of bean leaves with Botrytis cinerea. Physiol. Mol. Plant P 50, 151-166. doi: 10.1006/pmpp.1996.0076

Underwood, W. (2012). The plant cell wall: a dynamic barrier against pathogen invasion. Front. Plant Sci. 3:85. doi: 10.3389/fpls.2012.00085

Valette-Collet, O., Cimerman, A., Reignault, P., Levis, C., and Boccara, M. (2003). Disruption of Botrytis cinerea pectin methylesterase gene Bcpme1 reduces virulence on several host plants. Mol. Plant Microbe Interact. 16, 360-367. doi: 10.1094/MPMI.2003.16.4.360

Van Baarlen, P., Legendre, L., and Kan, J. A.,L (2007). "Plant defence compounds against botrytis infection," in Botrytis: Biology, Pathology and Control, eds Y. Elad, B. Williamson, P. Tudzynski, and N. Delen (Netherlands: Springer), $143-161$. 
Van Baarlen, P., Staats, M., and Van Kan, J. A. (2004). Induction of programmed cell death in lily by the fungal pathogen Botrytis elliptica. Mol. Plant Pathol. 5 , 559-574. doi: 10.1111/j.1364-3703.2004.00253.x

Van Kan, J. A. L. (2006). Licensed to kill: the lifestyle of a necrotrophic plant pathogen. Trends Plant Sci. 11, 247-253. doi: 10.1016/j.tplants.2006. 03.005

Van Kan, J. A. L., van't Klooster, J. W., Wagemakers, C. A. M., Dees, D. C. T., and van der Vlugt-Bergmans, C. J. B. (1997). Cutinase A of Botrytis cinerea is expressed, but not essential, during penetration of gerbera and tomato. Mol. Plant Microbe Interact. 10, 30-38.

Vincken, J. P., Schols, H. A., Oomen, R. J., McCann, M. C., Ulvskov, P., Voragen, A. G., et al. (2003). If homogalacturonan were a side chain of rhamnogalacturonan I. Implications for cell wall architecture. Plant Physiol. 132, 1781-1789. doi: 10.1104/pp.103.022350

Volpi, C., Janni, M., Lionetti, V., Bellincampi, D., Favaron, F., and D'Ovidio, R. (2011). The ectopic expression of a pectin methyl esterase inhibitor increases pectin methyl esterification and limits fungal diseases in wheat. Mol. Plant Microbe Interact. 24, 1012-1019. doi: 10.1094/MPMI-01-11-0021

Voragen, A. J., Coenen, G. J., Verhoef, R., and Schols, H. (2009). Pectin, a versatile polysaccharide present in plant cell walls. Struct. Chem. 20, 263-275. doi: 10.1007/s11224-009-9442-z

Wagstaff, C., Clarkson, G. J., Zhang, F., Rothwell, S. D., Fry, S. C., Taylor, G., et al. (2010). Modification of cell wall properties in lettuce improves shelf life. J. Exp. Bot. 61, 1239-1248. doi: 10.1093/jxb/erq038

Weiberg, A., Wang, M., Lin, F.-M., Zhao, H., Zhang, Z., Kaloshian, I., et al. (2013). Fungal small RNAs suppress plant immunity by hijacking host RNA interference pathways. Science 342, 118-123. doi: 10.1126/science.1239705

Wiemann, P., Sieber, C. M., von Bargen, K. W., Studt, L., Niehaus, E. M., Espino, J. J., et al. (2013). Deciphering the cryptic genome: genome-wide analyses of the rice pathogen Fusarium fujikuroi reveal complex regulation of secondary metabolism and novel metabolites. PLoS Pathog. 9:e1003475. doi: 10.1371/journal.ppat. 1003475

Wubben, J. P., ten Have, A., van Kan, J. M. L., and Visser, J. (2000). Regulation of endopolygalacturonase gene expression in Botrytis cinerea by galacutonic acid, ambient $\mathrm{pH}$ and carbon catabolite, repression. Curr. Gen. 37, 152-157. doi: $10.1007 / \mathrm{s} 002940050022$

Zhang, L., Hua, C., Stassen, J. H., Chatterjee, S., Cornelissen, M., and van Kan, J. A. L. (2013). Genome-wide analysis of pectate-induced gene expression in Botrytis cinerea: identification and functional analysis of putative d-galacturonate transporters. Fungal Genet. Biol. doi: 10.1016/j.fgb.2013.10.002. [Epub ahead of print].

Zhang, L., Kars, I., Essenstam, B., Liebrand, T. W., Wagemakers, L., Elberse, J., et al. (2014). Fungal endopolygalacturonases are recognized as microbe-associated molecular patterns by the arabidopsis receptor-like protein RESPONSIVENESS TO BOTRYTIS POLYGALACTURONASES1. Plant Physiol. 164, 352-364. doi: 10.1104/pp.113.230698

Zhang, L., and van Kan, J. A. L. (2013a). "14 Pectin as a barrier and nutrient source for fungal plant pathogens," in Agricultural Applications: The Mycota, ed F. Kempken (Berlin, Germany: Springer Berlin Heidelberg), 361-375.

Zhang, L., and van Kan, J. A. L. (2013b). Botrytis cinerea mutants deficient in d-galacturonic acid catabolism have a perturbed virulence on Nicotiana benthamiana and Arabidopsis, but not on tomato. Mol. Plant Pathol. 14, 19-29. doi: 10.1111/j.1364-3703.2012.00825.x

Zhao, Z., Liu, H., Wang, C., and Xu, J. R. (2014). Correction: comparative analysis of fungal genomes reveals different plant cell wall degrading capacity in fungi. BMC Genomics 15:6. doi: 10.1186/1471-2164-15-6

Conflict of Interest Statement: The authors declare that the research was conducted in the absence of any commercial or financial relationships that could be construed as a potential conflict of interest.

Received: 13 May 2014; accepted: 15 August 2014; published online: 03 September 2014

Citation: Blanco-Ulate B, Morales-Cruz A, Amrine KCH, Labavitch JM, Powell ALT and Cantu D (2014) Genome-wide transcriptional profiling of Botrytis cinerea genes targeting plant cell walls during infections of different hosts. Front. Plant Sci. 5:435. doi: $10.3389 /$ fpls.2014.00435

This article was submitted to Plant-Microbe Interaction, a section of the journal Frontiers in Plant Science.

Copyright (c) 2014 Blanco-Ulate, Morales-Cruz, Amrine, Labavitch, Powell and Cantu. This is an open-access article distributed under the terms of the Creative Commons Attribution License (CC BY). The use, distribution or reproduction in other forums is permitted, provided the original author(s) or licensor are credited and that the original publication in this journal is cited, in accordance with accepted academic practice. No use, distribution or reproduction is permitted which does not comply with these terms. 